\title{
¿Adaptation of the Predicted Particles Properties (P3) Microphysics Scheme for Large-Scale Numerical Weather Prediction
}

\author{
Caroline Jouan, ${ }^{\mathrm{a}}$ Jason A. Milbrandt, ${ }^{\mathrm{b}}$ Paul A. VAillancourt, ${ }^{\mathrm{b}}$ Frédérick Chosson, ${ }^{\mathrm{a}}$ And \\ HUGH MORRISON $^{\mathrm{c}}$ \\ ${ }^{\text {a }}$ Numerical Weather Prediction Development, Environment and Climate Change Canada, Dorval, Quebec, Canada \\ ${ }^{\mathrm{b}}$ Atmospheric Numerical Weather Prediction Research Section, Environment and Climate Change Canada, Dorval, Quebec, \\ Canada \\ ${ }^{\mathrm{c}}$ National Center for Atmospheric Research, Boulder, Colorado
}

(Manuscript received 4 July 2020, in final form 30 September 2020)

\begin{abstract}
A parameterization for the subgrid-scale cloud and precipitation fractions has been incorporated into the Predicted Particle Properties (P3) microphysics scheme for use in atmospheric models with relatively coarse horizontal resolution. The modified scheme was tested in a simple 1D kinematic model and in the Canadian Global Environmental Multiscale (GEM) model using an operational global NWP configuration with a $25-\mathrm{km}$ grid spacing. A series of 5-day forecast simulations was run using P3 and the much simpler operational Sundqvist condensation scheme as a benchmark for comparison. The effects of using P3 in a global GEM configuration, with and without the modifications, were explored through statistical metrics of common forecast fields against upper-air and surface observations. Diagnostics of state variable tendencies from various physics parameterizations were examined to identify possible sources of errors resulting from the use of the modified scheme. Sensitivity tests were performed on the coupling between the deep convection parameterization scheme and the microphysics, specifically regarding assumptions in the physical properties of detrained ice. It was found that even without recalibration of the suite of moist physical parameterizations, substituting the Sundqvist condensation scheme with the modified P3 microphysics resulted in some significant improvements to the temperature and geopotential height bias throughout the troposphere and out to day 5 , but with degradation to error standard deviation toward the end of the integrations, as well as an increase in the positive bias of precipitation quantities. The modified P3 scheme was thus shown to hold promise for potential use in coarse-resolution NWP systems.
\end{abstract}

KEYWORDS: Numerical weather prediction/forecasting; Short-range prediction; Cloud parameterizations; Clouds

\section{Introduction}

Clouds are an important component of the atmosphere due to their impacts on the general circulation and on the hydrological cycle. They affect longwave and shortwave radiative transfer, they affect atmospheric dynamics through latent heat release and absorption during phase changes of water and mass loading of condensate, and water is returned to the surface through precipitation. Despite their importance, the representation of clouds and cloud processes remain one of the largest sources of uncertainty in general circulations models (GCMs) and numerical weather prediction (NWP) models (Klein and Jakob 1999; Jiang et al. 2012; IPCC 2013).

In atmospheric models, clouds and precipitation are represented by a combination of physical parameterizations that are each targeted at a specific subset of moist processes. These include "implicit" (subgrid-scale) clouds generated by the boundary layer scheme and the convection parameterization-which is often subdivided into shallow, midlevel, and deep convection through separate parameterization schemes-and "explicit" clouds from the gridscale

¿ Denotes content that is immediately available upon publication as open access.

Corresponding author: Caroline Jouan, caroline.jouan@canada.ca condensation scheme (e.g., McTaggart-Cowan et al. 2019). Depending on the model grid spacing and the resulting degree to which different types of clouds are resolved, these "moist physics" schemes vary in their relative importance. For example, with horizontal grid spacings less than a few hundred meters, deep convection is considered to be resolved (Bryan et al. 2003; Lebo and Morrison 2015), and thus the convection parameterizations are not activated and moist physics is usually treated entirely by the "explicit" condensation scheme. Conversely, in models with horizontal grid spacings $>10 \mathrm{~km}$, convection schemes are necessary and generally play a larger role with coarser grid spacing (Grell and Freitas 2014).

Regardless of the resolution, the gridscale condensation scheme plays a crucial role in atmospheric models, though to different degrees and using different methods, depending on the grid spacing and the corresponding relative contributions of the implicit schemes. The terminology used in the scientific literature to describe condensation schemes is often inconsistent and confusing. To facilitate discussion in this article, the following terminology is used. A gridscale condensation scheme can, in general, be considered to consist of the following three components: 1) the subgrid cloud fraction parameterization (SCF, or cloud "macrophysics" scheme); 2) the microphysics scheme; and 3) the precipitation scheme. The cloud fraction (CF) provided by the SCF component is the percentage of the grid element that is covered by cloud (and is saturated), even though the gridscale relative humidity 
may be less than $100 \%$. The microphysics scheme computes the bulk effects of a complex set of cloud microphysical processes. If precipitating hydrometeors are advected by the model dynamics, the precipitation is said to be prognostic; if precipitation is assumed to fall instantly to the surface upon production, it is considered diagnostic. The precipitation "scheme" is not a separate component per se, since it simply reflects the level of detail in the microphysics parameterization, but it is a useful concept to facilitate the comparison of different gridscale condensation parameterizations.

With a wide range of grid spacings in current NWP models, there is a wide variety of types of condensation schemes and degrees of complexity in their various components. For example, convective scale models have typically used detailed bulk microphysics schemes (BMSs, i.e., the hydrometeor size distribution is assumed as an empirical function), inherently with no SCF component (the CF is either 0 or 1) and with prognostic precipitation, while large-scale global models use condensation parameterizations, sometimes referred to as "stratiform" cloud schemes, typically with much simpler microphysics and diagnostic precipitation but with more emphasis on the details of the SCF. However, with continually increasing computer resources and decreasing grid spacing (both in research and operational prediction systems), the distinction between schemes designed for specific ranges of model resolutions is disappearing and condensation schemes are being designed or modified to be more versatile and usable across a wider range of model resolutions. With many operational NWP systems now at the convective scale (HRDPS; ${ }^{1} \mathrm{HRRR}^{2}$ NAM CONUS nest; ${ }^{3}$ UKV-UM; ${ }^{4}$ AROME $;^{5}$ COSMO $^{6}$ ), detailed $\mathrm{BMSs}$ are now widely used as the gridscale condensation scheme.

Necessary modifications to adapt a BMS to increasing grid spacing include: 1) the incorporation of a nonbinary SCF; 2) possible modifications for use with large model time steps; and 3) possible simplifications to the parameterized microphysical processes (e.g., Forbes et al. 2012; Chosson et al. 2014; Dietlicher et al. 2018). Also, adapting a detailed BMS into a large-scale model generally includes recalibration of other moist parameterization schemes so that they work in optimal balance.

The Meteorological Service of Canada (MSC), which includes the government weather service of Environment and Climate Change Canada (ECCC), runs several NWP systems to provide numerical guidance at a range of spatial and

\footnotetext{
${ }^{1}$ 2.5-km High Resolution Deterministic Prediction System from Environment and Climate Change Canada.

23-km High-Resolution Rapid Refresh model from the National Oceanic and Atmospheric Administration.

${ }^{3}$ North American Mesoscale forecast system with a 3-km continental U.S. nest from the National Oceanic and Atmospheric Administration.

${ }^{4}$ United Kingdom Variable resolution (1.5 or $4 \mathrm{~km}$ ) part of the Met Office Unified Model.

51.3-km Applications de la Recherche à l'Opérationnel à MésoEchelle model from Météo-France.

${ }^{6} 1.1-\mathrm{km}$ Consortium for Small-Scale Modeling model from MeteoSwiss.
}

temporal scales. All MSC atmospheric prediction systems, including short-range and medium-range deterministic and ensemble NWP systems as well as a seasonal prediction system, use the Global Environmental Multiscale (GEM) weather prediction model (Côté el al. 1998; Girard et al. 2014). This article describes a continuation of a modernization project to unify the package of physical parameterizations used in MSC's operational NWP systems over a wide range of resolutions and for the general improvement of the global hydrological cycle (McTaggart-Cowan et al. 2019). While most of the atmospheric physical parameterizations in GEM have been updated, the gridscale condensation scheme used in most NWP systems has not been modified for many years.

Two different grid-scale condensation schemes are currently used in operational GEM-based NWP systems. In late 2018, the single-category configuration of the Predicted Particle Properties (P3) microphysics scheme (Morrison and Milbrandt 2015a, hereafter MM15a) was implemented into the High Resolution (2.5 km) Deterministic Prediction System (HRDPS; Milbrandt et al. 2016). In all of the other NWP systems at MSC, the Sundqvist et al. (1989) condensation scheme is used. The Sundqvist scheme uses a diagnostic SCF and a very simple microphysics component that includes a single prognostic variable for the total nonprecipitating condensate mass, and hence has diagnostic precipitation. In the past, the use of this scheme for all large-scale MSC prediction systems was justifiable, given the coarser model resolutions and limited computer resources. However, it has been recognized that Sundqvist is no longer appropriate for the current operational systems. For example, the Regional and Global Deterministic Prediction Systems (RDPS and GDPS, respectively) suffer from a systematic upwind displacement of precipitation (e.g., Mo et al. 2019), Sundqvist underpredicts ice water content (IWC) aloft (Chosson et al. 2014), and a prescribed (constant) effective radius of ice crystals is used for the computation of cloud optical properties for the radiative transfer scheme. Thus, a more detailed condensation scheme-with a better representation of in-cloud microphysical processes and with prognostic precipitation-could be beneficial to some MSC prediction systems.

To this end, development has been done at ECCC to adapt the P3 microphysics scheme for use in coarser resolution models. In P3, a new approach to represent ice was proposed by MM15a and Milbrandt and Morrison (2016), where a userspecified number of freely evolving (i.e., not predefined) icephase hydrometeor categories are used. It was shown in Morrison and Milbrandt (2015b) that even with a single ice category, the P3 scheme can simulate different types of weather events at least as well or better than traditional (category-based), state-of-the-art schemes, and at a reduced computational cost. Although originally developed as a proofof-concept research scheme, it soon became clear that P3 could be suitable for kilometer-scale NWP systems. In the work presented herein, P3 was modified by incorporating a SCF scheme, thereby allowing for subgrid-scale clouds to form and exist in subsaturated grid boxes. The SCF is similar to the one used in Sundqvist, where the diagnostic cloud fraction is based on a height-dependent relative humidity threshold. 
The objectives of this article are to document the changes made to the P3 scheme and to examine the effects in a NWP context. We also explore the requirements of properly interfacing P3 with the deep convection scheme. Tests are performed using a $25-\mathrm{km}$ GEM configuration based on the operational GDPS. The remainder of this article is organized as follows. Section 2 provides a description of the modified cloud microphysics scheme as well as an illustration of its general behavior in a simple 1D model. Section 3 summarizes the different techniques used at ECCC to validate the GEM NWP systems under development. Section 4 examines the potential of the modified P3 scheme for use in GEM compared with the operational Sundqvist scheme. The importance of realistically interfacing the modified cloud microphysics and deep convection schemes is addressed in section 5. Concluding comments are given in section 6 .

\section{Description of the modified cloud microphysics scheme}

\section{a. Overview of the P3 scheme}

A complete description of the P3 scheme version used as the starting point of the development described in the following section can be found in MM15a. A brief overview of the scheme is provided here. Table 1 lists the symbols used in this article. The liquid phase of P3 is a typical two-moment, two-category scheme, with prognostic equations for the mass mixing ratios $q$ and number mixing ratios $N$ of cloud water and rain. The particle size distribution (PSD) of each category is described by a complete gamma function. P3 scheme differs from the traditional category-based microphysics schemes by abandoning the use of predefined ice-phase types (e.g., ice, snow, etc.) with fixed parameters for bulk physical properties and predicts the continuous evolution of the physical properties of "free" ice-phase hydrometeors through a careful selection of prognostic variables. In the 2.5-km HRDPS and in this work, P3 uses one ice-phase category whose PSD is described by a complete gamma function and with four prognostic variables: the total ice mass mixing ratio $q_{-} i$,tot , the rime mass mixing ratio $q_{-} i$,rim, the total ice number mixing ratio $N_{i, \text { tot }}$, and the bulk rime volume mixing ratio $B_{-} i$,rim. These prognostic variables have been specifically chosen in order to predict important ice physical properties, such as bulk particle density, rime mass fraction, mean particle size, etc. The evolution of any prognostic microphysical variable $\varphi \in\left\{q_{c}, q_{r}, N_{c}, N_{r}, q_{-} i\right.$, tot,$q_{-} i$,rim, $N_{-} i$,tot,$B_{\_} i$,rim $\}$ has the form:

$$
\frac{\partial \varphi}{\partial t}+\mathbf{u} \cdot \nabla \varphi=\left.\frac{\partial \varphi}{\partial t}\right|_{\text {micro }}+\left.\frac{\partial \varphi}{\partial t}\right|_{\text {sedi }},
$$

where the left-hand side includes the dynamical tendencies (advection), $\mathbf{u}$ is the wind vector, and the terms on right-hand side are the microphysical process rates (source/sink terms) and sedimentation tendencies, respectively. The source/sink terms include microphysical process rates such as nucleation, diffusional growth, collision-collection, freezing, and melting.
TABLE 1. List of symbols.

\begin{tabular}{|c|c|c|}
\hline Symbol & Description & Units \\
\hline$a$ & Cloud fraction & - \\
\hline$B_{i, \text { rim }}$ & Volume mixing ratio, rime ice & $\mathrm{m}^{3} \mathrm{~kg}^{-1}$ \\
\hline$N_{c}^{-t, 1110}$ & Number mixing ratio, cloud & $\mathrm{kg}^{-1}$ \\
\hline$N_{i \_ \text {detrain }}$ & Number mixing ratio of detrained ice & $\mathrm{kg}^{-1}$ \\
\hline$N_{i_{-} \text {tot }}$ & Number mixing ratio, total ice & $\mathrm{kg}^{-1}$ \\
\hline$N_{r}$ & Number mixing ratio, rain & $\mathrm{kg}^{-1}$ \\
\hline$q_{c}$ & Mass mixing ratio, cloud & $\mathrm{g} \mathrm{kg}^{-1}$ \\
\hline$q_{\text {cond }}$ & $\begin{array}{l}\text { Mass mixing ratio, condensate } \\
\quad(\text { cloud }+ \text { total ice })\end{array}$ & $\mathrm{g} \mathrm{kg}^{-1}$ \\
\hline 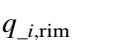 & Mass mixing ratio, rime ice & $\mathrm{g} \mathrm{kg}^{-1}$ \\
\hline$q_{-} i$, tot & Mass mixing ratio, total ice & $\mathrm{g} \mathrm{kg}^{-1}$ \\
\hline$q_{\min }$ & Minimum mixing ratio for cloudy air & $\mathrm{g} \mathrm{kg}^{-1}$ \\
\hline$q_{r}$ & Mass mixing ratio, rain & $\mathrm{g} \mathrm{kg}^{-1}$ \\
\hline$q_{\text {sat }}$ & Saturation mixing ratio & $\mathrm{g} \mathrm{kg}^{-1}$ \\
\hline$q_{t}$ & Mass mixing ratio, total mass & $\mathrm{g} \mathrm{kg}^{-1}$ \\
\hline$q_{t}^{\text {cld }}$ & Mean in-cloud total water mixing ratio & $\mathrm{g} \mathrm{kg}^{-1}$ \\
\hline$q_{t}^{\text {clr }}$ & Mean clear-sky total water mixing ratio & $\mathrm{g} \mathrm{kg}^{-1}$ \\
\hline$q_{v}^{\text {cld }}$ & Mean in-cloud mixing ratio, vapor & $\mathrm{g} \mathrm{kg}^{-1}$ \\
\hline$q_{v}^{\mathrm{clr}}$ & Mean clear-air mixing ratio, vapor & $\mathrm{g} \mathrm{kg}^{-1}$ \\
\hline$\Delta q$ & Width of the PDF of total water mixing ratio & $\mathrm{g} \mathrm{kg}^{-1}$ \\
\hline$\overline{q_{\text {cond }}}$ & Grid-mean mass mixing ratio, condensate & $\mathrm{g} \mathrm{kg}^{-1}$ \\
\hline$\overline{q_{t}}$ & Grid-mean mass mixing ratio, total & $\mathrm{g} \mathrm{kg}^{-1}$ \\
\hline$\overline{q_{v}}$ & Grid-mean mass mixing ratio, vapor & $\mathrm{g} \mathrm{kg}^{-1}$ \\
\hline$\overline{q_{-} i, \mathrm{tot}}$ & Grid-mean mass mixing ratio, total ice & $\mathrm{g} \mathrm{kg}^{-1}$ \\
\hline$\overline{q_{c}}$ & Grid-mean mass mixing ratio, cloud & $\mathrm{g} \mathrm{kg}^{-1}$ \\
\hline $\mathrm{CWC}$ & Cloud water content & $\mathrm{g} \mathrm{kg}^{-1}$ \\
\hline IWC & Ice water content & $\mathrm{g} \mathrm{kg}^{-1}$ \\
\hline CWP & Cloud water path & $\mathrm{kg} \mathrm{m}^{-2}$ \\
\hline IWP & Ice water path & $\mathrm{kg} \mathrm{m}^{-2}$ \\
\hline RWP & Rainwater path & $\mathrm{kg} \mathrm{m}^{-2}$ \\
\hline$r_{e, c}$ & Effective radius, cloud (droplets) & $\mathrm{m}$ \\
\hline$r_{e, i}$ & Effective radius, ice & $\mathrm{m}$ \\
\hline $\mathrm{RH}_{\mathrm{cr}}$ & Critical relative humidity & - \\
\hline$r_{m, i}$ & Volume-mean radius, ice & $\mathrm{m}$ \\
\hline$T$ & Air temperature & ${ }^{\circ} \mathrm{C}$ \\
\hline$T_{d}$ & Dewpoint temperature & ${ }^{\circ} \mathrm{C}$ \\
\hline$Z_{g}$ & Geopotential height & $\mathrm{m}$ \\
\hline
\end{tabular}

\section{b. The subgrid cloud and precipitation fraction component}

The adaptation of a detailed BMS for use in models with large grid spacings $(>10 \mathrm{~km})$ requires the implementation of a subgrid cloud fraction (SCF) component. The approach described in Chosson et al. (2014) has been applied to P3. In addition to providing a $\mathrm{CF}$, this scheme also diagnoses the fraction of the grid where precipitation is likely to occur, which may be different from the CF; thus, the full parameterization is referred to as the SCPF (subgrid cloud and precipitation fraction). The SCPF scheme uses a simple diagnostic method to represent the fraction of the grid box where cloud formation and decay occur. It is based on an assumed fixed-width top-hat PDF to represent the subgrid-scale variability of total water mass mixing ratio, uniformly distributed around its grid-mean value $\overline{q_{t}} \pm \Delta q$ (see Fig. 1 ). The term $\overline{q_{t}}$ is the sum of grid-mean water vapor mixing ratio $\overline{q_{v}}$ and grid-mean cloud condensate mixing ratio $\overline{q_{\text {cond }}}$, the latter defined as cloud water mixing ratio $\overline{q_{c}}$, plus total ice mixing ratio $\overline{q_{i} i \text {,tot }}$. From the saturated portion of the PDF, one can diagnose the cloud fraction $a$ and the mean 


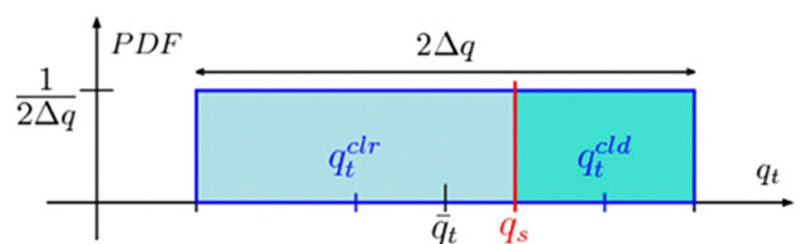

FIG. 1. Assumed fixed-width top-hat distribution function of total water mixing ratio within the grid box. The area above saturation to the right of $q_{\text {sat }}$ represents the subgrid cloud fraction. Reprinted from Chosson et al. (2014). (C) American Meteorological Society. Used with permission.

in-cloud total water mixing ratio $q_{t}^{\text {cld }}$ (see Fig. 1). For the subsaturated portion, one can diagnose the mean clear-sky total water mixing ratio $q_{t}^{\text {clr }}$ (see Fig. 1). As the cloud condensate is present only in the cloudy fraction of the grid box, one can also derive the in-cloud mean water vapor mixing ratios $q_{v}^{\text {cld }}$ and the cloud-free mean water vapor mixing ratios $q_{v}^{\text {clr }}$. From the prognostic grid-mean variables of $\overline{q_{t}}, \overline{q_{\text {cond }}}$ and saturation mixing ratio (with respect to liquid or ice, depending on the temperature) $q_{\text {sat }}$, one can obtain the cloud fraction $a$, and the in-cloud mean $q_{v}^{\text {cld }}$ and cloud-free mean $q_{v}^{\text {clr }}$, through the following equations:

$$
\begin{aligned}
a & =\frac{\overline{q_{t}}+\Delta q-q_{\mathrm{sat}}}{2 \Delta q}, \quad \text { with } \quad 0 \leq a \leq 1 ; \\
q_{v}^{\mathrm{cld}} & =q_{t}^{\mathrm{cld}}-q_{\mathrm{cond}}^{\mathrm{cld}}=\frac{\overline{q_{t}}+\Delta q+q_{\mathrm{sat}}}{2}-\frac{\overline{q_{\mathrm{cond}}}}{a} \\
q_{v}^{\mathrm{clr}} & =q_{t}^{\mathrm{clr}}=\frac{\overline{q_{t}}-\Delta q+q_{\mathrm{sat}}}{2} .
\end{aligned}
$$

An empirical relationship between the $\operatorname{PDF}$ width $(\Delta q$ is a measure of the subgrid moisture variability) and a vertical profile of the critical threshold relative humidity $\mathrm{RH}_{\mathrm{cr}}$, described in Fig. 2 (as implemented in the operational GEM model for the Sundqvist scheme), is established:

$$
\Delta q=q_{\mathrm{sat}}\left(1-\mathrm{RH}_{\mathrm{cr}}\right) .
$$

Note that $q_{v}^{\mathrm{clr}}=\overline{q_{v}}$ when the $\mathrm{CF}$ is zero.

The fact that precipitation can appear within a fraction only of the cloud is also taken into account and Chosson et al. (2014) also proposed an initial subgrid precipitation fraction potentially different from the cloud fraction that triggers the precipitation, whose effect is to increase the precipitation production. In the modified P3, cloud droplets and ice particles are considered to be uniformly distributed within the cloudy fraction part of the grid cell, and rain drops are considered to be uniformly distributed within the precipitation fraction part of the grid cell. As will be shown in section 4, an already positive moist precipitation bias was exacerbated by the transition to the modified P3, so the precipitation fraction is set equal to the cloud fraction in this work. A maximum-random overlap assumption is employed to determine how clouds overlap with each other in the model column (Geleyn and Hollingsworth 1979). In situations where cloud water and ice sediment into a subsaturated environment ( $a=0)$, it is assumed that the precipitation fraction takes the value of the computed cloud fraction at the above

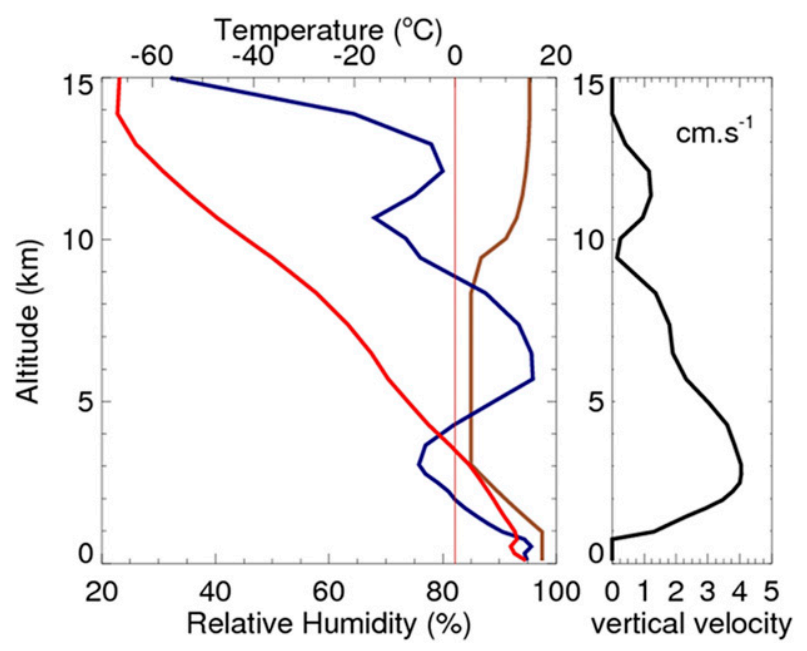

FIG. 2. Initial profiles of temperature (red), relative humidity (blue), and vertical velocity (black) for the 1D kinematic model experiments. The critical threshold relative humidity $\mathrm{RH}_{\mathrm{cr}}$ (brown) above which the condensation is allowed in the Sundqvist and SCPF schemes is also shown. Reprinted from Chosson et al. (2014). (C) American Meteorological Society. Used with permission.

level, without any modification of the local cloud-free mean water vapor mass mixing ratio.

At the beginning of the P3 time step, the SCPF component provides the in-cloud mean values of $\overline{q_{x}}$ and $\overline{N_{x}}$, that is, $q_{x}=\overline{q_{x}} / a$ and $N_{x}=\overline{N_{x}} / a$ for $x=c$ or $\_i$,tot, required to calculate the in-cloud mean microphysical processes rates. The gridmean rates are then obtained by multiplying the in-cloud mean rates by the $\mathrm{CF}$. For liquid condensation/evaporation (CON/EVP) and ice deposition/sublimation (DEP/SUB), the in-cloud mean $q_{v}^{\text {cld }}$ or cloud-free mean $q_{v}^{\text {clr }}$ value of water vapor mixing ratio is used to compute the in-cloud and cloud-free mean saturation mixing ratio, and the result is multiplied by its corresponding CF; $q_{v}^{\text {cld }}$ is also used for ice melting (MLT) and wet growth of ice (WET) as P3 adopts the relative humiditydependent Lin et al. (1983) and Musil (1970) parameterizations for these processes, respectively. All prognostic microphysical variables are then updated with these grid-mean tendencies. The SCPF scheme is called again before sedimentation to update the in-cloud mean values of $\overline{q_{x}}$ and $\overline{N_{x}}$ for the calculation of the physical hydrometeors properties and the bulk fall speed needed for sedimentation. At the end of the microphysics time step, the SCPF then provides the CF, which is used by the radiative transfer scheme.

Large-scale NWP models use much longer time steps than kilometer-scale models, for which detailed BMSs were originally designed, thus adaptation of a detailed microphysics scheme may also require modification for use with longer time steps. This is essentially an optimization, but it is necessary for consideration in an operational model. In the implementation of P3 in GEM, the microphysics routine is substepped (i.e., it is called multiple times consecutively) such that the time step used by the microphysics has a maximum value of $60 \mathrm{~s}$. This is done primarily because in $\mathrm{P} 3$ the microphysical process rates are computed and applied separately from sedimentation, 
which means that with large model time steps and no substepping hydrometeors can sediment a great distance without any interaction with the environment; the microphysics substepping mitigates this problem. Also, further substepping within the sedimentation computation (which is essentially $1 \mathrm{D}$ advection) is performed to ensure numerical stability.

\section{c. Coupling with the deep convection scheme}

The gridscale condensation schemes (Sundqvist and P3) interact directly in GEM with the deep convection and radiative transfer schemes. The convection schemes may detrain anvil, mid and low-level condensate to the gridscale scheme. Detrained condensate is provided to the microphysics by simply adding the ice and/or water mass(es) to the appropriate prognostic hydrometeor mixing ratio variable(s). Additional assumptions, described in section 5, about total number mixing ratio(s) are needed since $\mathrm{P} 3$ is a two-moment scheme. The radiative transfer scheme requires the $\mathrm{CF}$ and cloud optical properties (cloud optical depth, single scattering albedo, and asymmetry factor) from the combined implicit schemes and the gridscale condensation scheme. This $\mathrm{CF}$ for the radiation scheme is computed assuming random overlap between clouds from each source (moist parameterization) when using Sundqvist. With P3, random overlap is assumed for implicit sources and minimum overlap is then assumed between these clouds and the explicit clouds from P3 (with or without the $\mathrm{SCPF}$ ). The optical properties are parameterized as a function of cloud water/ice water path (CWP, IWP) and cloud water/ice effective radius $\left(r_{e, c}, r_{e, i}\right)$ and are thus highly dependent on the details of the microphysics. CWP and IWP are computed directly by summing cloud water and ice mass mixing ratio provided by each cloud source. The total condensate mass from Sundqvist is partitioned diagnostically into cloud water and ice (Boudala et al. 2004) and $r_{e, c}$ values are computed as a function of the CWP and an assumed droplet number concentration, depending on the surface type (ocean and land). Limits of 4 and $17 \mu \mathrm{m}$ are imposed on $r_{e, c}$, whereas $r_{e, i}$ is assumed to have a fixed value of $15 \mu \mathrm{m}$ everywhere. In P3, the effective radius is directly computed from the PSD of each hydrometeor category. These values are directly used to compute the cloud optical properties. Limits of 4-40 $\mu \mathrm{m}$ and $10-70 \mu \mathrm{m}$ are imposed on $r_{e, c}$ and $r_{e, i}$, respectively, in order to respect the limits of the radiation tables used in GEM (McTaggart-Cowan et al. 2019; Milbrandt et al. 2018). For the implicit clouds, $r_{e, c}$ is computed as described above for clouds from Sundqvist except that $r_{e, i}$ is assumed to have a fixed value of $30 \mu \mathrm{m}$. The optical properties from the explicit and implicit sources are then aggregated leading to the final computed values that are used for the subsequent radiative transfer calculations.

\section{d. Test in a $1 D$ kinematic model}

The modified P3 scheme is first tested with a simple 1D kinematic column model (described in Milbrandt et al. 2014) to illustrate that the code produces physically reasonable results. Table 2 lists the condensation scheme configurations used in this study. The first three were tested in the $1 \mathrm{D}$ model and include the version of the Sundqvist scheme used in GEM (SUND), the single-category P3 scheme (P3), and the modified
TABLE 2. List of simulations and their modifications in GEM.

\begin{tabular}{ll}
\hline \multicolumn{1}{c}{ Runs } & \multicolumn{1}{c}{ Details } \\
\hline SUND & $\begin{array}{l}\text { Sundqvist-based cloud microphysics scheme } \\
\text { Original version of P3 cloud microphysics } \\
\text { scheme } \\
\text { Podified version of P3 with the subgrid cloud } \\
\text { and precipitation fraction scheme }\end{array}$ \\
P3_SCPF_Rmi20 & $\begin{array}{l}\text { As in P3_SCPF, but with a prescribed volume } \\
\text { mean radius } r_{m, i} \text { on the order of } 20 \mu \mathrm{m}, \text { used } \\
\text { to derive the total number mixing ratio of ice } \\
\text { crystals detrained from the deep convection }\end{array}$ \\
& scheme into the explicit P3 scheme \\
P3_SCPF_Rmi40 & $\begin{array}{c}\text { As P3_SCPF_Rmi20, but with } r_{m, i}=40 \mu \mathrm{m} \\
\text { As P3_SCPF_Rmi20, but with } r_{m, i}=60 \mu \mathrm{m}\end{array}$ \\
\hline
\end{tabular}

P3 scheme with the SCPF component activated (P3_SCPF). SUND is included here for comparison since it contains a SCF with similar relative humidity criteria to diagnose the $\mathrm{CF}$ as in P3_SCPF (Fig. 2) and the behavior of Sundqvist (in GEM) is known. Weak upward air motion is prescribed in the 1D model for the first $3 \mathrm{~h}$, followed by downward motion (Figs. 2 and 3 ), mimicking a typical nonconvective gridscale vertical velocity in a large-scale $(\sim 25 \mathrm{~km}) 3 \mathrm{D}$ model. The $1 \mathrm{D}$ model is initialized with the same sounding used in Chosson et al. (2014) to represent a deep midlevel cloud layer with overlying cirrus. The column is divided into 51 vertical levels with a constant grid spacing of $245 \mathrm{~m}$ and a top at $15-\mathrm{km}$ altitude. The time step used is $60 \mathrm{~s}$ and the duration of the simulations is $360 \mathrm{~min}$.

Figures $3 \mathrm{a}-\mathrm{c}$ show time evolution of the vertical profiles of the $\mathrm{CF}$, condensate water paths and precipitation rates. For P3 and P3_SCPF, the cloud water path (CWP), rainwater path (RWP), and ice water path (IWP) are the vertical integrals of the cloud water, rainwater, and ice mass contents, respectively. For SUND, the cloud water path (CWP) and ice water path (IWP) are the vertical integrals of the total condensate mass content, partitioned into liquid and ice based on temperature.

For $\mathrm{P} 3$, the CF in a grid point is 1 if there is any "cloud" and 0 otherwise, where it is considered "cloudy" if either $q_{c}>q_{\mathrm{min}}$ and/or if both $q_{-} i$,tot $>q_{\min }$ and $r_{e, i}<100 \mu \mathrm{m}$ (otherwise the ice is considered to be precipitation and does not contribute to cloudiness) with $q_{\min }=10^{-14} \mathrm{~kg} \mathrm{~kg}^{-1}$. Even though both P3_ SCPF and SUND have the same relative humidity threshold, higher CF values are produced with SUND compared to P3_ SCPF (Figs. 3e,f). Compared to SUND, P3 allows ice particles to consume the available moisture by diffusional growth in a more realistic way (in principle), which may explain the increase of $q_{-} i$,tot in $\mathrm{P} 3$.

The fact the SCPF allows condensation before the gridscale saturation is achieved may explain why the overlying thin ice cloud is absent in P3 but present in P3_SCPF and SUND.

Condensation occurs earlier in P3_SCPF and SUND and there are greater peak values of the water paths and cloud lifetime compared to P3 (Figs. 3d-f). The higher quantity of surface precipitation in P3_SCPF compared to P3 is attributable to the earlier generation of condensate with the SCPF scheme leading to more production of rainwater aloft. SUND takes longer to produce precipitation at the surface than 
a)

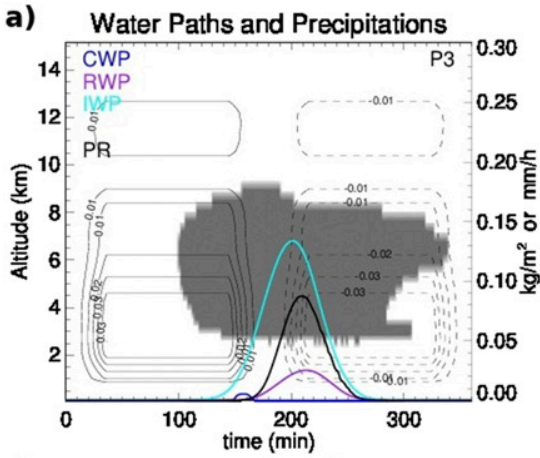

d)

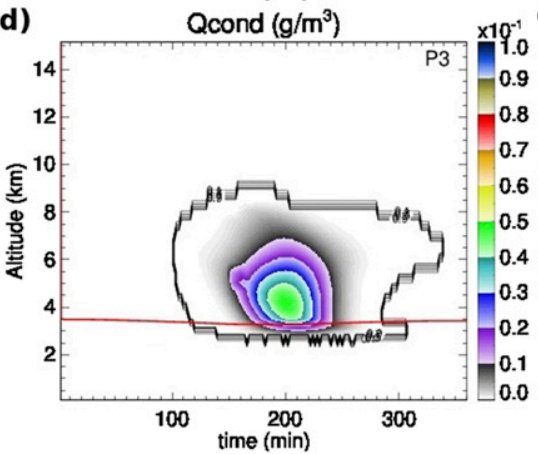

b)

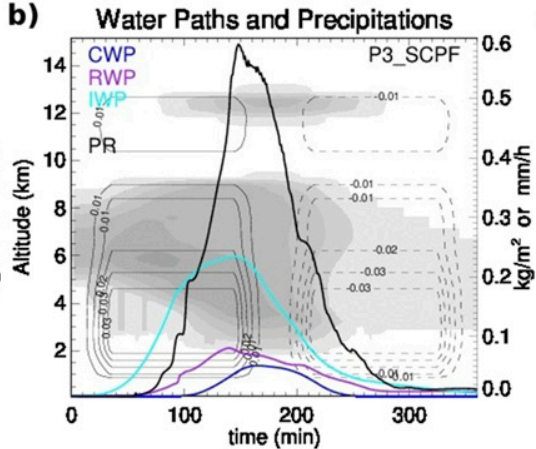

c) Water Paths and Precipitations

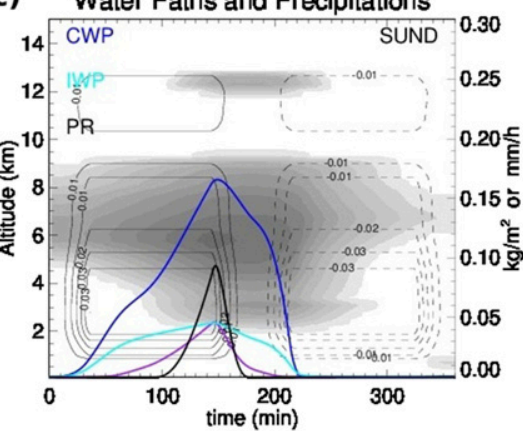

e)
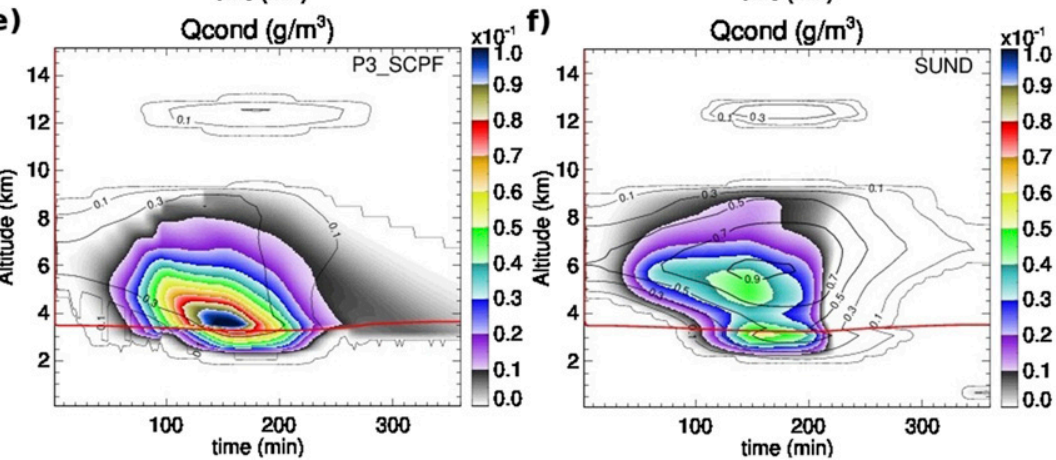

FIG. 3. Simulation results from (left) P3, (center) P3_SCPF, and (right) SUND. (a)-(c) Time evolution of the column-integrated water paths of the cloud water (blue), rain (magenta), and ice (cyan) with the surface precipitation rates (black) and the subgrid cloud fraction as background filled contours (10\% per gray level, starting at $10 \%)$. Note that the purple curve in (c) is equivalent to RWP, calculated by vertical integration of the rain fluxes provided by SUND at each level, times $\Delta t$. The prescribed vertical velocity is superimposed in solid (positive values) or dashed (negative) isolines. (d)-(f) Total cloud condensate with the subgrid cloud fraction superimposed in isocontours and the $0^{\circ} \mathrm{C}$ isoline (red).

P3_SCPF and has overall smaller surface rain rates. Given that the CWP and cloud fraction are smaller in P3_SCPF (Figs. 3b,e), despite having the same forcing applied, we hypothesize that the differences in precipitation rates are related to a much higher precipitation efficiency in P3_SCPF owing to a combination of smaller autoconversion rates compared to SUND and that greater removal of cloud water through accretion by the prognostic precipitation (i.e., a more physical/better representation of ice/droplet interaction compared to SUND).

The interface of the new SCPF component in P3 appears to give reasonable results in the $1 \mathrm{D}$ model, at least in terms of the desired effects of producing clouds and possibly precipitation before gridscale saturation is reached. Having illustrated that the modified P3 appears to be working correctly and as intended, it is now practical to examine in detail its behavior in a more realistic 3D model context.

\section{Data and methodology}

To examine further the impacts of the SCPF component of the modified P3, the three condensation schemes discussed in the previous section have been used to run a series of

TABLE 3. Summary of GEM model configuration.

\begin{tabular}{ll}
\hline \hline \multicolumn{1}{c}{ Model aspect } & \multicolumn{1}{c}{ Details } \\
\hline Grid & Horizontal grids: $417 \times 417$ points, $\Delta x=25 \mathrm{~km}$ \\
& Vertical grid: 84 staggered hybrid levels \\
Time step & $\Delta t=720 \mathrm{~s}$ \\
Model initialization scheme & 4D incremental analysis update (4D-IAU) applied over a 6-h assimilation window (i.e., from $t-3 \mathrm{~h}$ \\
& to $t+3 \mathrm{~h}$ ) (Buehner et al. 2015) \\
Shallow convective scheme & Bechtold scheme (Bechtold et al. 2001) \\
Deep convective scheme & Kain-Fritsch scheme (Kain and Fritsch 1990, 1993) \\
Planetary boundary layer scheme & TKE with statistical representation of subgrid-scale cloudiness (MoisTKE) (Bélair et al. 2005) \\
Radiation scheme & Li-Barker correlated- $k$ distribution radiative transfer scheme (called every 1 h) (Li and Barker 2005) \\
Surface scheme & Interactions between Soil, Biosphere, and Atmosphere (ISBA) land surface scheme (Noilhan and \\
& Planton 1989; Bélair et al. 2003) \\
\hline
\end{tabular}




\section{a) CERES}

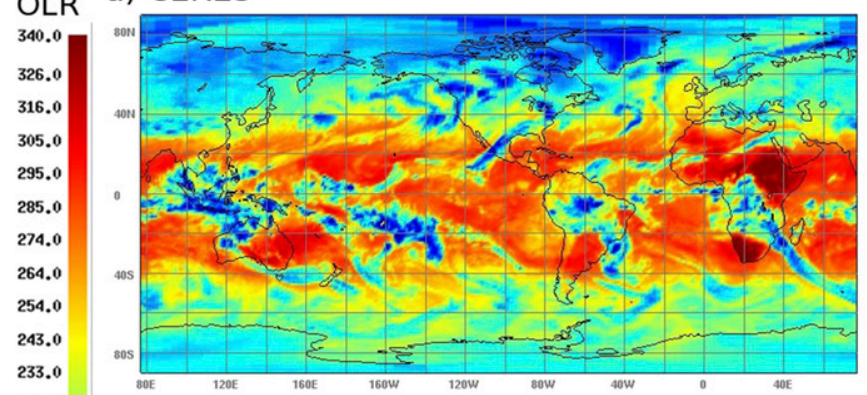

\begin{tabular}{l|l}
223.0 & b) SUND \\
212.0 &
\end{tabular}

\begin{tabular}{l|}
212.0 \\
202.0 \\
192.0 \\
182.0 \\
171.0 \\
161.0 \\
151.0 \\
140.0 \\
130.0 \\
120.0 \\
109.0 \\
100.0
\end{tabular}

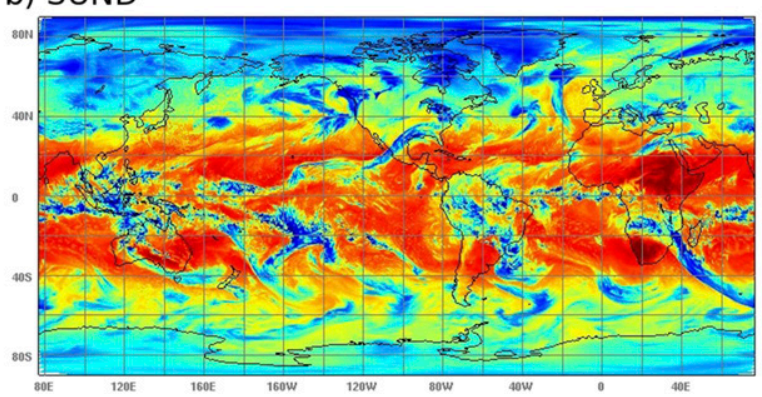

c) P3

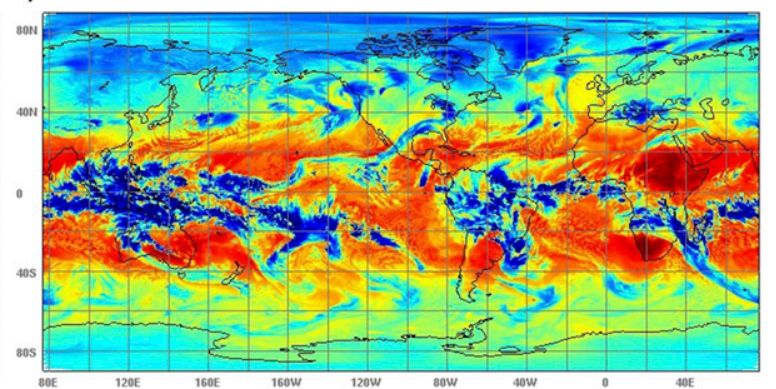

d) P3_SCPF_Rmi60

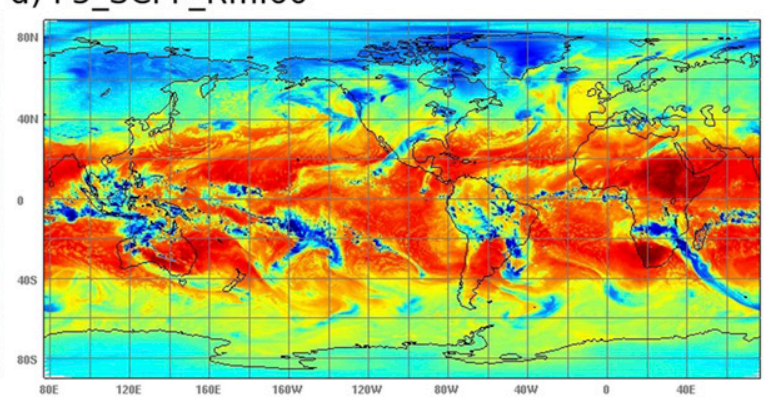

FIG. 4. (a) Observed and (b)-(d) simulated all sky outgoing longwave radiation (OLR; $\mathrm{W} \mathrm{m}^{2}$ ) at the top-of-the-atmosphere at $1200 \mathrm{UTC}$ 17 Jan 2017.

"hindcast" simulations using GEM with a configuration based on MSC's operational global model, and are evaluated in the following section. In this section, the various formal verification techniques used at ECCC to validate the NWP systems under development are described.

\section{a. The NWP system framework}

All operational deterministic and ensemble NWP systems run at MSC use the GEM forecast model (Côté et al. 1998; Girard et al. 2014). GEM is a nonhydrostatic atmospheric model that solves the fully compressible Euler equations using implicit time differencing and semi-Lagrangian advection. GEM uses an Arakawa-C grid in the horizontal (Mesinger and Arakawa 1976) and a Charney-Philips grid in the vertical (Charney and Phillips 1953), with staggered thermodynamic and momentum levels. The operational Global Deterministic Prediction System (GDPS) uses a yin-yang grid, which consists of two overlapping limited-area domains around the globe, similar to a baseball (Qaddouri and Lee 2011).

The GEM simulations presented below were run with a 25-km global grid, with a configuration based on the GDPS (see Table 3). Note, the grid spacing of the operational GDPS was recently decreased to $15 \mathrm{~km}$ (McTaggart-Cowan et al. 2019). The larger grid spacing used in this study provides a more rigorous testing of the modified $\mathrm{P} 3$ since the SCPF plays a more important role at coarser resolution. Furthermore, this scale continues to be of interest to operational NWP (e.g., for global ensemble and seasonal prediction systems). A limited number of tests (not shown) were also performed with a $15-\mathrm{km}$ grid spacing; the overall findings were similar to those with $25 \mathrm{~km}$.

\section{b. Standard skill scores}

For consideration of changes to NWP system configurations to be implemented operationally, they are evaluated

TABLE 4. Average in time and in space (global) of radiative fluxes $\left(\mathrm{W} \mathrm{m}^{-2}\right)$ at the top of the atmosphere (TOA) and at the surface (SFC) as well as the average planetary albedo (AP) during the 5-day integration started from the analysis of 1200 UTC 5 Jul 2016 SUND, for the three experiments SUND, P3, and P3_SCPF. "LW" and "SW" indicate shortwave and longave radiation, respectively. "UP" and "DN" indicate upwelling and downwelling fluxes. "Rnet" is the net radiative flux.

\begin{tabular}{lcccccr}
\hline \hline & SUND & P3 & P3_SCPF & P3_SCPF_Rmi20 & P3_SCPF_Rmi40 & P3_SCPF_Rmi60 \\
\hline LWUP_TOA & 243.31 & 232.74 & 236.37 & 237.05 & 247.17 & 249.61 \\
SWUP_TOA & 96.94 & 127.68 & 101.02 & 101.28 & 95.87 & 94.82 \\
Rnet_TOA & -10.57 & -30.74 & -7.71 & -8.65 & -13.36 & -14.75 \\
LWDN_SFC & 355.89 & 364.04 & 356.62 & 356.64 & 355.91 & 176.34 \\
SWDN_SFC & 177.39 & 138.98 & 171.37 & 171.06 & 101.63 & 177.49 \\
Rnet_SFC & 102.34 & 76.78 & 97.68 & 97.44 & 0.291 & 102.55 \\
AP & 0.294 & 0.387 & 0.306 & 0.307 & 0.288 \\
\hline
\end{tabular}




\section{Lead Time: $24 \mathrm{~h}$ (day 1$)$ \\ GLOBAL}
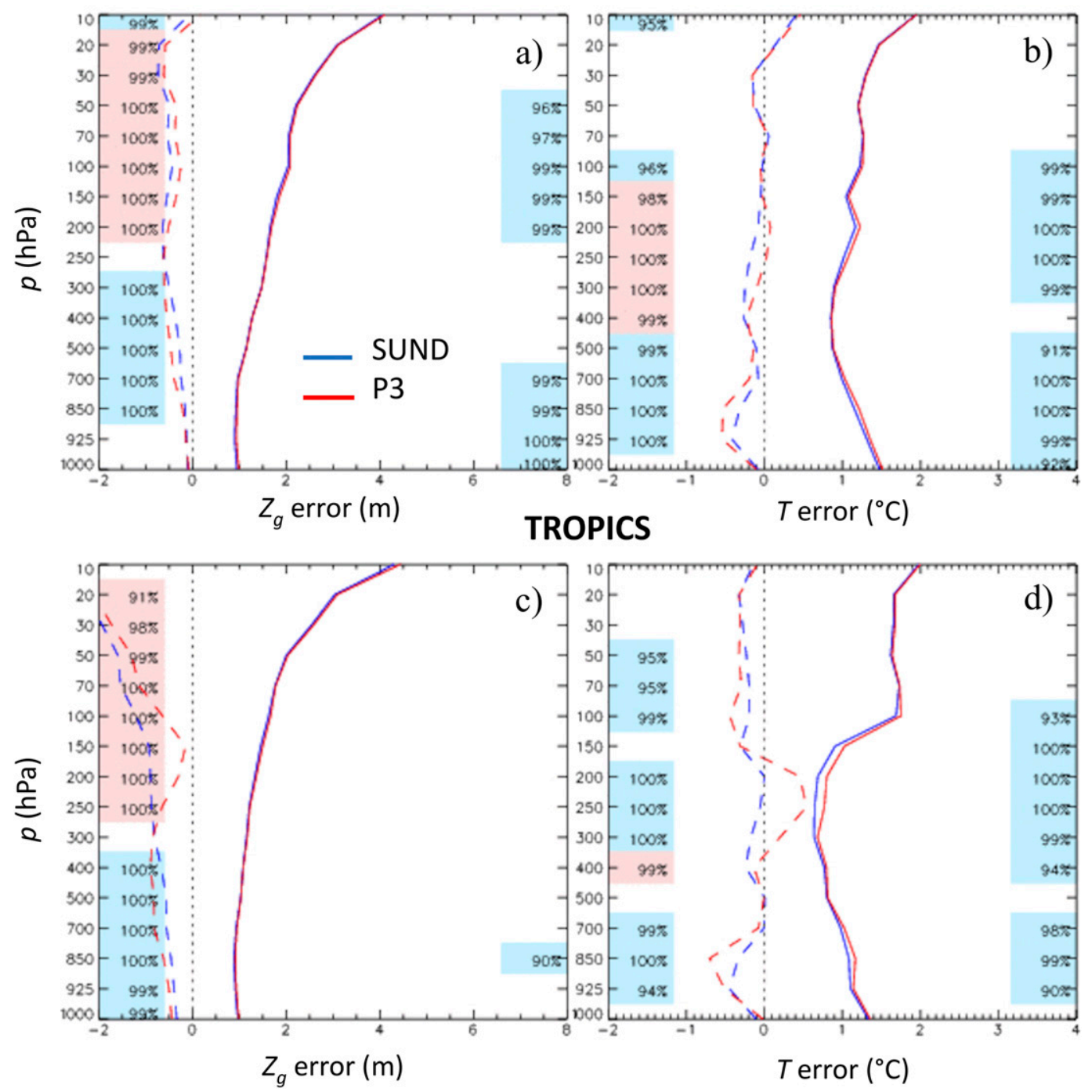

FIG. 5. (a)-(f) Preliminary sensitivity experiments for the 2016 summer season in global, and tropical regions on day 1 . Vertical profiles (pressure levels; hPa) of biases (dashed lines), and standard deviation (solid lines) of geopotential height errors and temperature forecast errors against radiosonde data averaged over 40 cases during the summer of 2016, for experiment P3 (in red) compared to the control forecasts SUND (in blue). The statistical significance of the difference between forecast errors (left, bias and right, standard deviation) is indicated at each level by blue or red boxes, such that blue boxes represent a forecast degradation and red boxes an improvement relative to SUND. The tropical region is defined as the area within $20^{\circ}$ of the equator.

objectively by comparing forecast skill scores of the experimental version to the operational configuration (the control). At ECCC, a set of 80 reference cases ( 40 winter and 40 summer) is typically used. The runs start at 0000 or 1200 UTC for 5 -day integrations and are separated by $36 \mathrm{~h}$ to provide meteorologically independent cases. The winter cases used in this study span the period from 0000 UTC 16 December 2016 to 1200 UTC 18 February 2017; the summer cases are from 1200 UTC 17 June 2016 to 0000 UTC 21 August 2016.
Standard skill scores (bias and standard deviation) for model forecasts are then computed against radiosonde observations to evaluate the upper-air fields such as the temperature $T$, dewpoint depression $T-T_{d}$, geopotential height $Z_{g}$, zonal $U$, and meridional $V$ wind speeds over the globe and specific regions. The scores are computed at every 24-h lead time. The dataset includes radiosondes whose measurements are tied to international reference standards (Laroche and Sarrazin 2013). 


\section{Lead Time: $120 \mathrm{~h}$ (day 5)}

\section{GLOBAL}
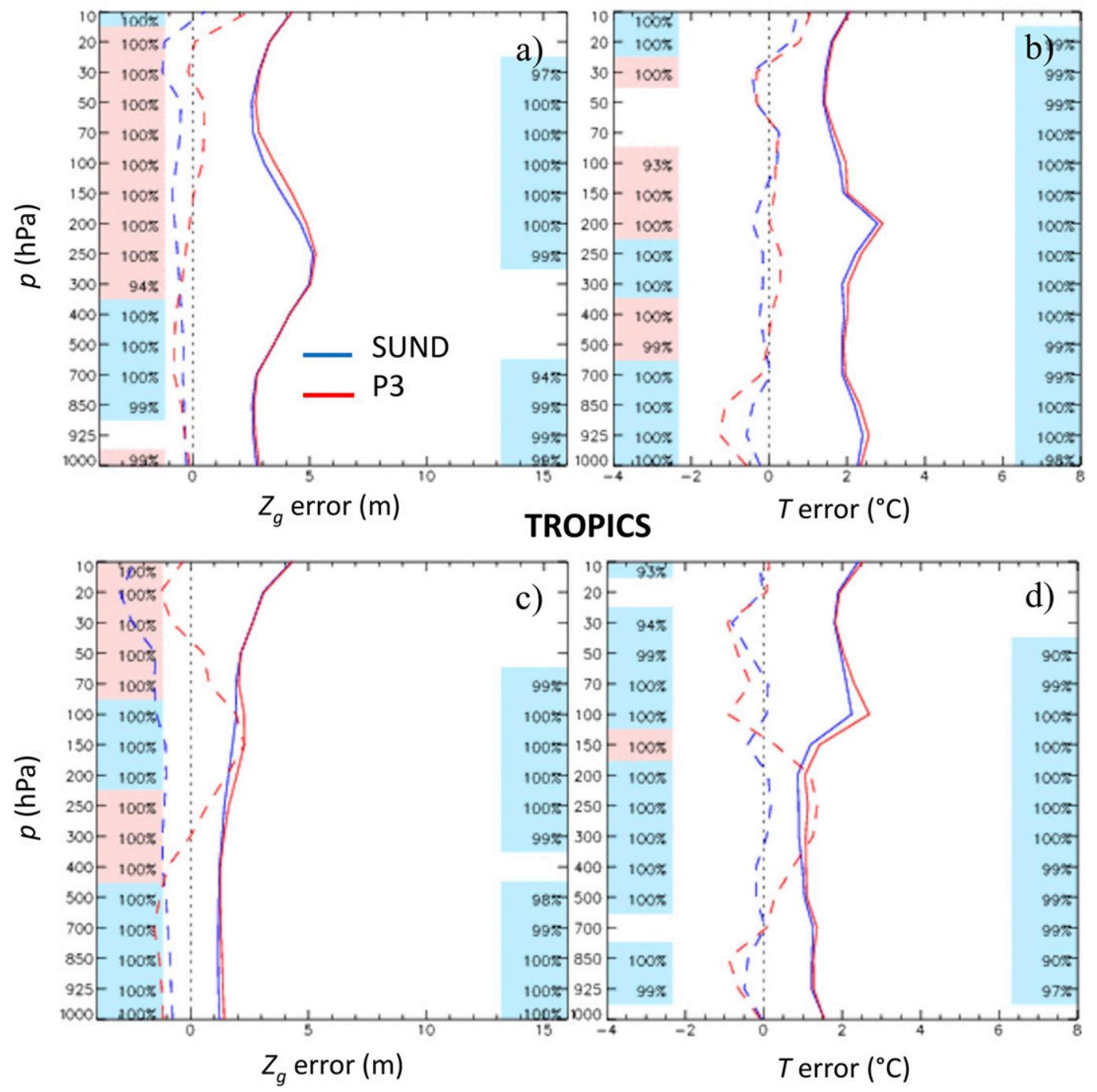

FIG. 6. As in Fig. 5, but on day 5.

The 24-h accumulated precipitation (PR24) surface field is evaluated through the frequency bias index (FBI) calculated using the nearest neighbor over North America. The FBI is the ratio between the number of simulated events and the number of observed events, that is, it indicates the tendency to overestimate $(>1)$ or underestimate $(<1)$ precipitation events according to different thresholds. Quality check controls were performed based on the Canadian Precipitation Analysis for precipitation observations (CaPA; Mahfouf et al. 2007; Lespinas et al. 2015) and based on an algorithm specific to MSC's station-based verification package (EMET; Lemay and Husson 2017).

\section{c. Tendency diagnostic}

A tendency diagnostic tool, described in Zadra et al. (2014), was used to assess the first-order impact of the modified P3 scheme to physical changes in the GEM simulations. For 5-day integrations, temperature and moisture tendencies were extracted from all the contributing parameterizations as well as from the dynamics (i.e., resolved transport tendencies). All tendencies were averaged in time and in space over the globe and over specific regions. To complete the tendency diagnostic, time averaged vertical profiles of macro and microphysical properties and time series of the total precipitation rate, spatially averaged over certain regions, were calculated. The state variables averaged in time and globally such as the planetary albedo (AP) and the radiative flux at the top of the atmosphere (TOA) and surface (SFC) give a good indication of the cloud radiative effect. Verification of the planetary albedo makes it possible to ensure good radiative balance of the model. Satellite observations indicate that the 


\section{Lead Time: $24 \mathrm{~h}$ (day 1$)$ \\ GLOBAL}
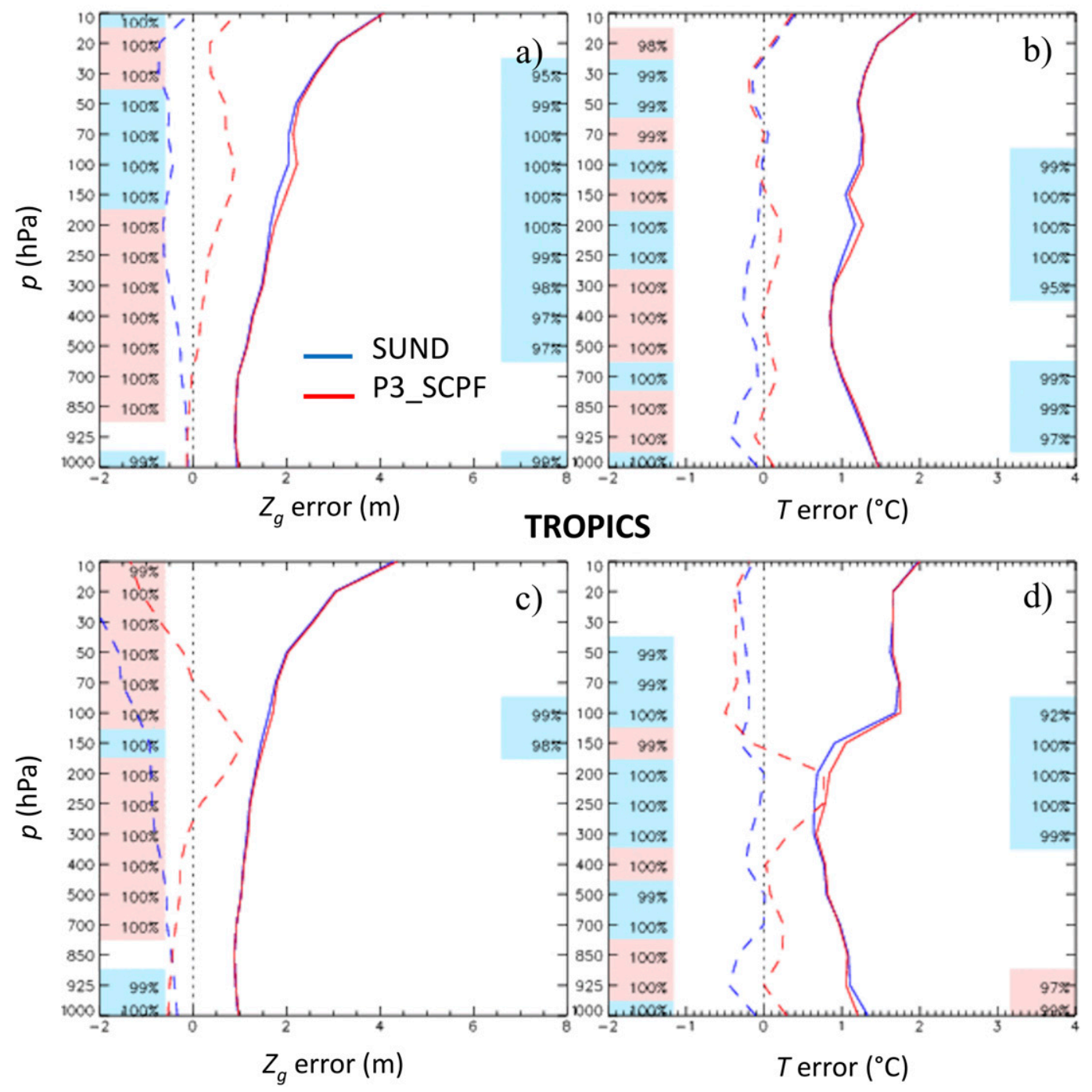

FIG. 7. As in Fig. 5, but for experiment P3_SCPF (in red) compared to the control forecasts SUND (in blue) on day 1.

planetary albedo is near 30\%-33\% (ISCCP, Rossow and Zhang 1995).

\section{Impacts of using P3 (and SCPF) in a global model}

In this section, we examine the effects of using P3, with and without the SCPF activated, in the $25-\mathrm{km}$ global GEM configuration. A series of 5-day forecasts were run using SUND, P3, and P3_SCPF. The Sundqvist scheme has been used in the GDPS for many years and the GEM physics parameterizations (moist schemes and radiative transfer) have been calibrated to work optimally with this scheme; thus, SUND run series serves as a control. It was expected that the default P3 would result in degraded scores (and this is indeed what the evaluation below shows), because it was designed for near cloud-resolving model configurations and no calibration with the other physics schemes was done. Comparison of results with P3 and P3_ SCPF, with SUND as a reference point, allow further evaluation of the new SCPF component.

\section{a. Effects on clouds}

Figure 4 provides a qualitative visual glance at the impacts of the different model configurations described in Table 4 on clouds through the all sky outgoing longwave radiation (OLR) at the TOA. The observations come from the Clouds and the Earth's Radiant Energy System (CERES) SYN1deg-1Hour products that are Level 3 products containing $1^{\circ}$ hourly averaged observed TOA OLR (Doelling et al. 2013, 2016) from the 


\section{Lead Time: $120 \mathrm{~h}$ (day 5) \\ GLOBAL}
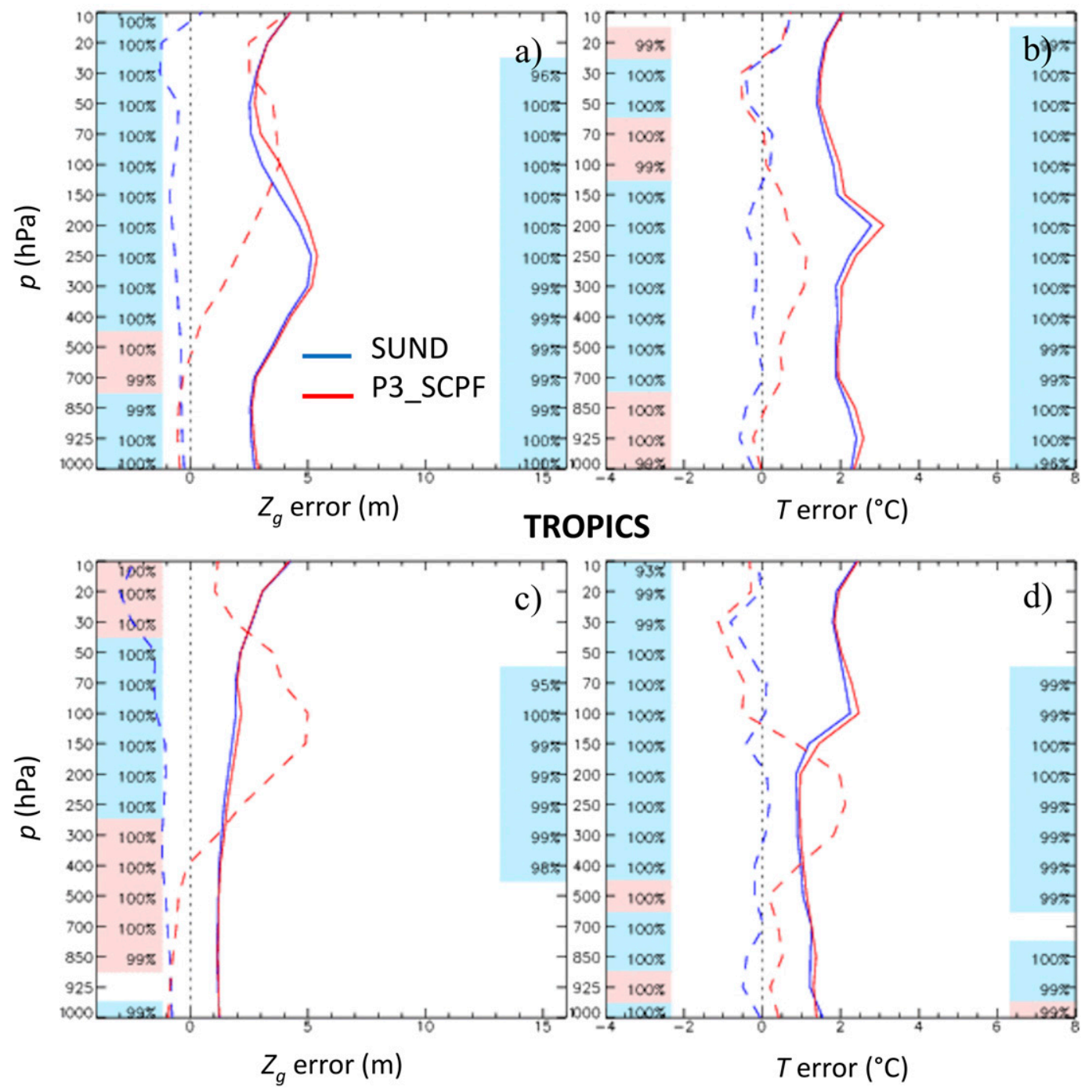

FIG. 8. As in Fig. 5, but for experiment P3_SCPF (in red) compared to the control forecasts SUND (in blue) on day 5 .

National Aeronautics and Space Administration (NASA). The lowest values of OLR seen in the tropics correspond to cold cloud tops of cirrus anvils. While Fig. 4b shows that with SUND, the cirrus anvil cover is too low and the cloud tops are too warm (low), Fig. 4c shows that with P3 (similar with P3 SCPF, not shown), the coverage becomes significantly overestimated in the convective areas of the tropics.

\section{b. Preliminary standard skill scores}

Figures 5-8 present skill scores for $Z_{g}$ and $T$ at lead times of 24 and $120 \mathrm{~h}$ and for the globe and the tropics. Differences in skill scores for dewpoint depression and wind speeds between the configurations exhibit similar sensitivity as in the analysis of $T$, therefore they are not shown. As seen in Figs. 5 and 6, significant degradations in scores with $\mathrm{P} 3$ are evident early in the integrations (at 24 h; Fig. 5) and they amplify over time (at day 5; Fig. 6). These are at a maximum in the upper tropical troposphere (Figs. 5e,f and 6e,f) but are also present in other regions and in the winter season (not shown). In particular, it can be seen that below $500 \mathrm{hPa}$, with $\mathrm{P} 3$ the cold bias increases compared to SUND and the bias grows in time (Figs. 5b, d, f and $6 \mathrm{~b}, \mathrm{~d}, \mathrm{f})$. Above $500 \mathrm{hPa}, \mathrm{P} 3$ behaves in the opposite way, resulting in a warm bias compared to SUND. This is more prominent in the tropics (Figs. $5 \mathrm{f}$ and $6 \mathrm{f}$ ). The $Z_{g}$ is also deteriorated with $\mathrm{P} 3$ in mid and upper levels in the tropics.

In contrast, P3_SCPF results in a warm bias over most of the column (Figs. 7b,d,f and 8b,d,f). The bias below $500 \mathrm{hPa}$ is similar or even slightly better than SUND, and greatly 


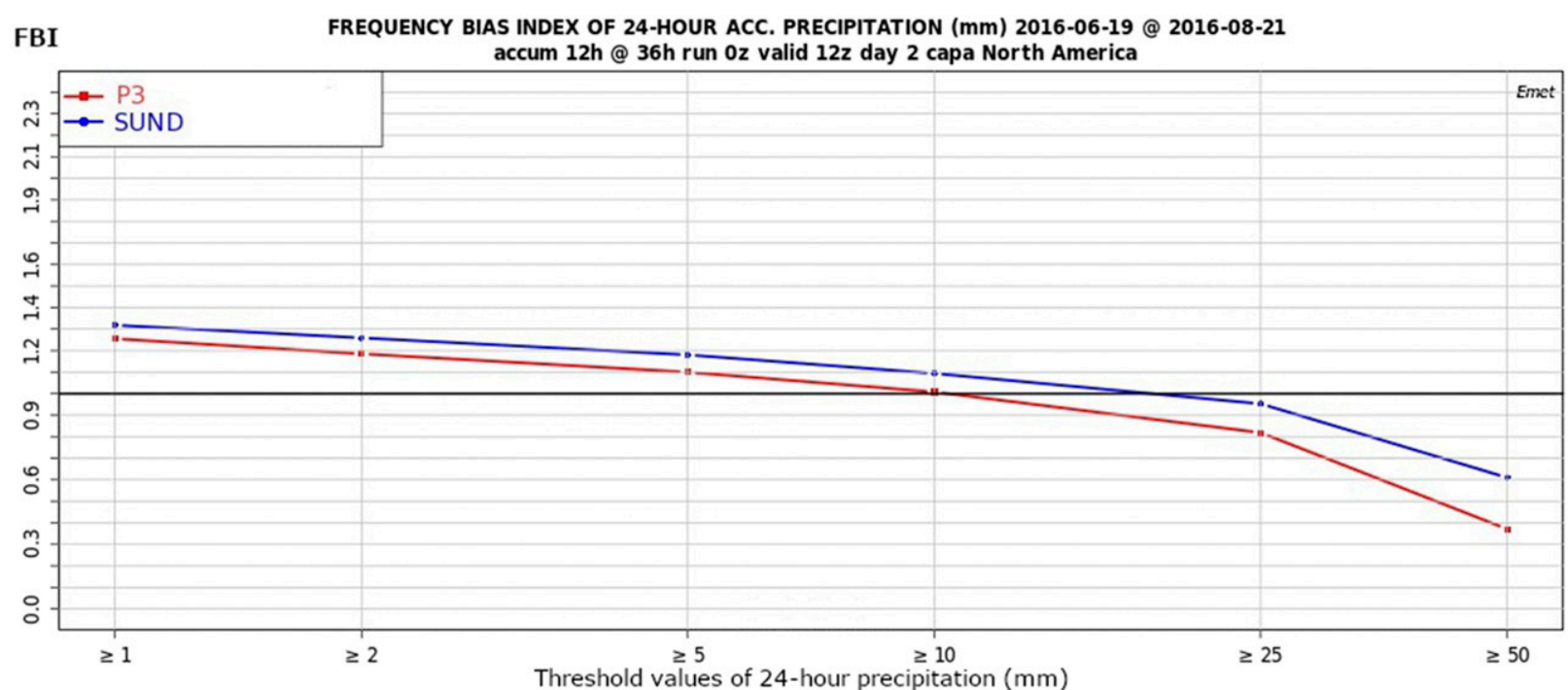

Difference $\left|S_{2}-1\right|-\left|S_{1}-1\right|$

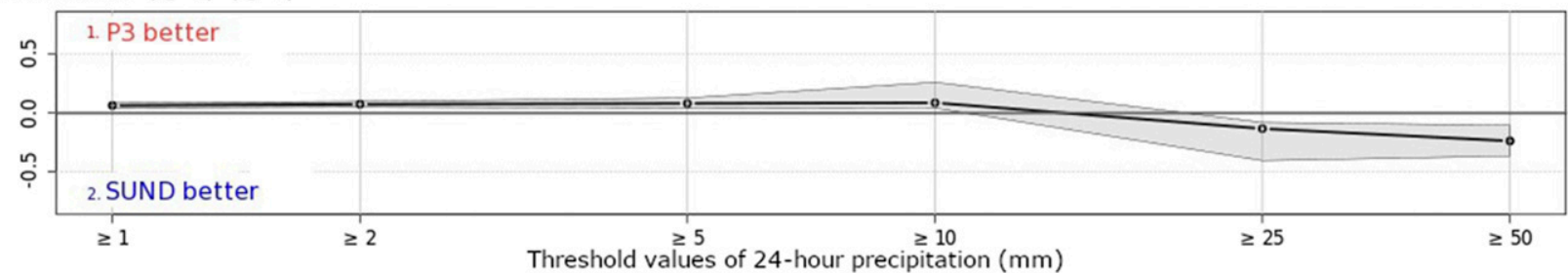

FIG. 9. (top) Frequency bias index (FBI) of the 24-h accumulated precipitation over North America for experiment P3 (in red) compared to the control forecasts SUND (in blue) and the associated statistical differences (bottom) with the $90 \%$ confidence range (in shading).

improved compared to P3. This suggests that it is possible to reduce errors in $T$ at lower levels and improve the simulation by coupling P3 to SCPF. However, in mid and upper levels, the warm bias is accentuated, even compared to P3, which deteriorates that aspect of the forecasts throughout the integration, especially in the tropics (Figs. $7 \mathrm{f}$ and $8 \mathrm{f}$ ). The same applies to the $Z_{g}$ bias, which is reduced with P3, improving the simulation (except for the tropics), but accentuated toward a positive bias with P3_SCPF resulting in a notable deterioration (Figs. 7a,c,e and $8 \mathrm{a}, \mathrm{c}, \mathrm{e})$.

Figures 9 and 10 show the FBI as a function of precipitation thresholds for P3 and P3_SCPF, respectively, compared to SUND over North America. The bias is slightly improved in P3 for thresholds less than $10 \mathrm{~mm}$ and slightly deteriorated for higher amounts. P3_SCPF has the opposite effect. As in the 1D simulations, P3_SCPF produces considerably more precipitation in GEM compared to P3 and SUND. These results show that the switch to a condensation scheme with detailed microphysics, with or without a CF component, has considerable impact on the simulation, even at a lead time of $24 \mathrm{~h}$. Negative impacts appear to be maximum in the tropics in the upper troposphere (cirrus anvil region) as well as in the boundary layer.

\section{c. Impact on model tendencies, radiation, and cloud properties}

To understand better the direct impact of P3 and P3_SCPF as well as the indirect effects through interactions with the other physics parameterizations, a tendency diagnostic is performed on simulations from a single case, supplemented by an analysis of the radiation and cloud properties. Starting from the analysis of 1200 UTC 5 July 2016, 5-day integrations were performed with SUND, P3, and P3_SCPF. Figure 11 shows vertical profiles of the $\mathrm{CWC}$, IWC, and $\mathrm{CF}$, averaged in time and in space, as seen by the radiative transfer scheme. The tendencies for $T$ and $Q$ (water vapor mixing ratio) are shown in Figs. 12 and 13, respectively.

The SCPF component reduces the $\mathrm{CF}$, as seen by comparison of P3 and P3_SCPF (Fig. 11c). This affects the shortwave radiation. Table 4 gives the average radiative fluxes at the TOA and at the surface for all simulations. At the TOA, the upward flux of shortwave radiation increases from $96.94 \mathrm{~W} \mathrm{~m}^{-2}$ in SUND to $127.69 \mathrm{~W} \mathrm{~m}^{-2}$ in P3 leading to an increase of the planetary albedo (PA) from 0.294 to 0.387. The reduced CF in P3_SCPF makes it possible to rebalance the net shortwave radiation and thus to reduce the PA to a value of 0.306 , which is closer to reality $(30 \%-33 \%$ form ISCCP, Rossow and Zhang 1995) (Table 4). At mid and upper levels, P3 and P3_SCPF produce higher IWC than SUND (Fig. 11b). Note, cloud ice is treated much differently in P3 than Sundqvist, which has diagnostic precipitation and thus does not retain precipitating ice across time steps. Moreover, P3 includes moisture depletion by diffusional growth of ice (including precipitating particles) more realistically, which helps explain the increase of IWC in P3 and 
FBI

FREQUENCY BIAS INDEX OF 24-HOUR ACC. PRECIPITATION (mm) 2016-06-19 @ 2016-08-21 accum $12 \mathrm{~h} @ 36 \mathrm{~h}$ run $0 z$ valid $12 \mathrm{z}$ day 2 capa North America

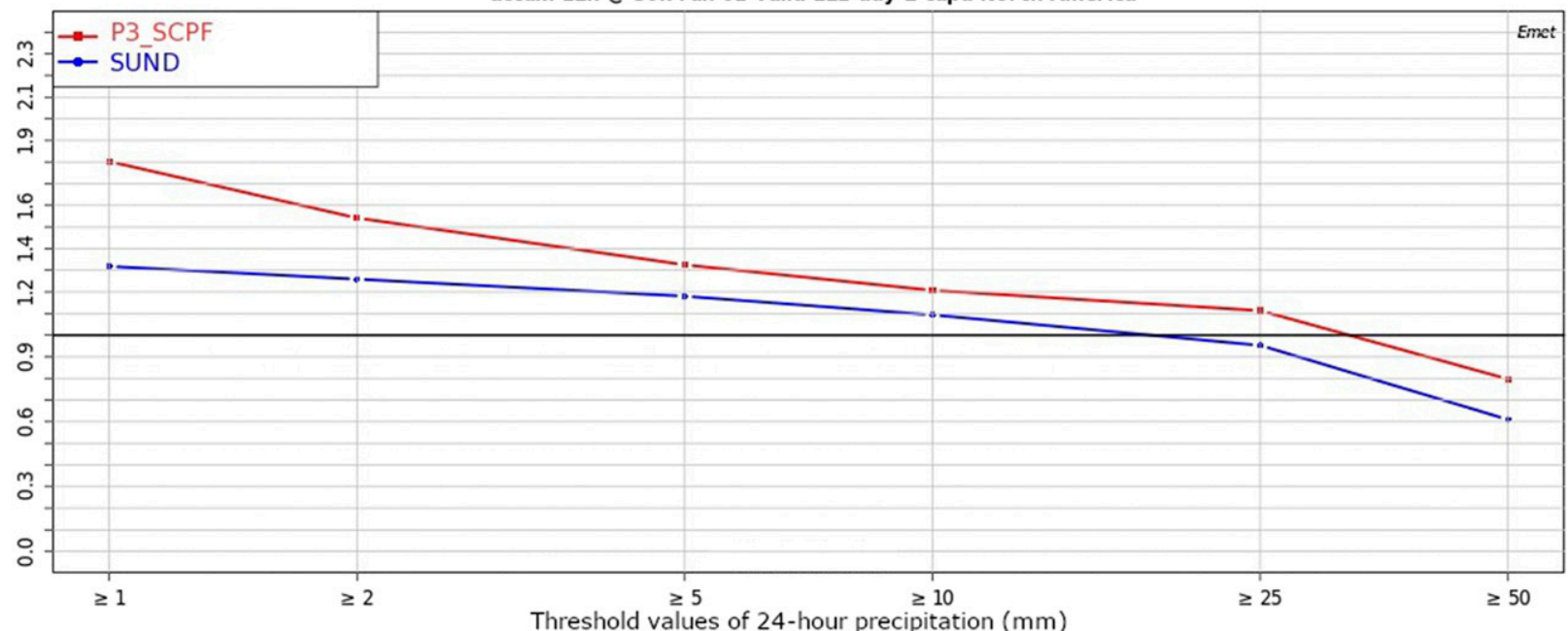

Difference $\left|S_{2}-1\right|-\left|S_{1}-1\right|$

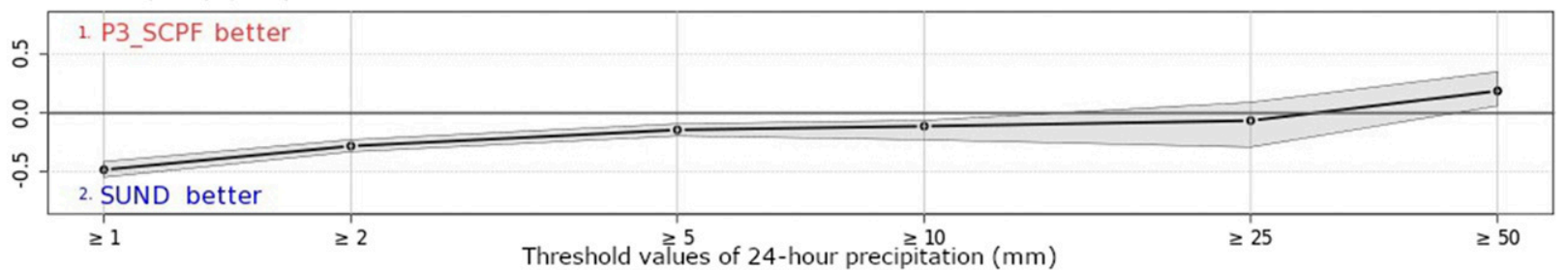

FIG. 10. As in Fig. 9, but for experiment P3_SCPF (in red) compared to the control forecasts SUND (in blue).

P3_SCPF. The tendency of P3_SCPF is to warm (Fig. 12d) and to dry slightly (Fig. 13b) the air in anvil cirrus clouds compared to P3 and SUND. These clouds are detrained from the deep convection scheme (Figs. 12c and 13a). These tendency changes partly compensate for those in the deep convection scheme. The increase of IWC in the mid and upper levels, both in P3 and P3_SCPF compared to SUND, strongly affects both the shortwave and longwave radiation (Figs. 12a,b). The optically thicker cirrus layers in P3 and P3_SCPF result in extra absorption and heating from the shortwave as well as a relative warming from upwelling longwave below the cirrus clouds relative to SUND. This is consistent with the upper-air scores showing an increase of $T$ with altitude (Figs. 5-8) related to the higher IWC in P3 and P3_SCPF compared to SUND. Chosson et al. (2014) showed that the Sundqvist scheme underpredicts IWC aloft in GEM, so the higher IWC with P3 suggests the potential for general simulation improvements with a switch to a detailed condensation scheme. However, results seen in Fig. 4c show that the increase in IWC is probably exaggerated in $\mathrm{P} 3$.

At low levels P3 produces higher CWC than P3_SCPF and SUND (Fig. 11a). This is consistent with the tendency of P3 to cool (Fig. 12d) and to moisten (Fig. 13b) due to evaporation or sublimation of low-level clouds, which originate primarily from detrainment by the shallow convection scheme (Figs. 12e and 13c), more so than with P3_SCPF or SUND. These tendency changes partly compensate for those in the shallow convection scheme. Reduced CWC in P3_SCPF compared to P3 is also consistent with the $1 \mathrm{D}$ model tests showing earlier production of condensate and greater production of rain using the SCPF component (Fig. 3).

The P3 scheme interacts with the deep convection scheme by gridscale condensate tendencies (solid and liquid) from the latter, through detrainment of condensate, and produces much higher IWC than SUND. This suggests that it may be possible to improve the results by modifying the coupling between P3 and the deep convection scheme.

\section{Sensitivity to detrained anvil cirrus clouds properties}

In GEM, the deep convective scheme detrains condensate to the gridscale condensation scheme through tendencies of prognostic variable(s) (ice and/or liquid) for condensate mass. With Sundqvist, this is straightforward since it has a single variable for the total, nonprecipitating cloud condensate. Since P3 is a two-moment scheme for all hydrometeor categories, it is necessary to make assumptions about the mean particle sizes and/or total number mixing ratios of the detrained ice $N_{i-\text { detrain }}$ and/or liquid since the current convection schemes in GEM only consider mass. In the original implementation of P3 in GEM, the coupling with the deep convection scheme is described as follows. For a positive liquid condensate mass tendency from convection, the detrained droplet number added to the microphysics scheme is prescribed based on an assumed concentration of 

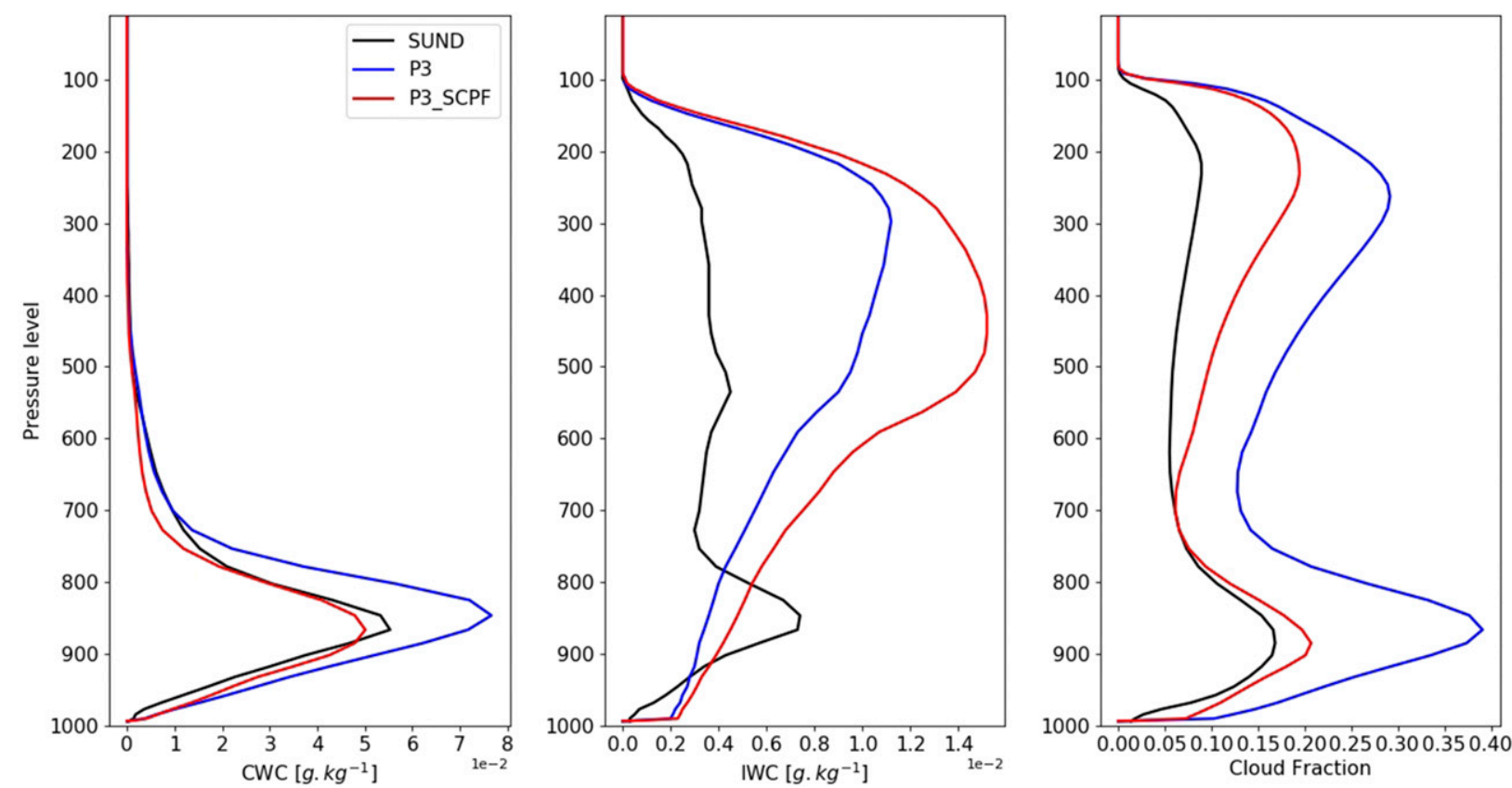

FIG. 11. Vertical profiles of the (a) cloud water content, (b) the ice water content, and (c) the cloud fraction averaged in time and in space (global) during the 5-day integration started from the analysis of 1200 UTC 5 Jul 2016 SUND, for the three experiments SUND, P3, and P3_SCPF.

background cloud condensation nuclei $\left(\mathrm{CCN} ; 80 \mathrm{~cm}^{-3}\right)$ or, if gridscale cloud water is already present, the new final $N_{c}$ is recalculated by assuming the mean size of detrained droplets is equal to that of existing cloud at a given grid point. Similarly, for a positive ice mass tendency from the convective scheme, $N_{i \_ \text {detrain }}$ is prescribed by either temperaturedependent ice nucleation parameterization (Cooper 1986) or, if gridscale ice is already present, $N_{i \text { detrain }}$ is recalculated by assuming a mean size of detrained ice is the same as the existing ice. $\mathrm{P} 3$ also predicts the rime mass $q_{-} i$,rim and bulk rime volume $B_{-} i$,rim mixing ratios of ice. Detrained ice is assumed to be frozen drops, thus the new $q_{-} i$,rim is assumed to be equal to the total (rime plus deposition) ice mass $q_{-} i$, tot and the new $B_{-} i$,rim is prescribed such that the bulk density is $917 \mathrm{~kg} \mathrm{~m}^{-3}$.

However, simulation results can be quite sensitive to the assumptions of the detrained ice properties when the microphysics scheme is two-moment (e.g., Grell et al. 2018). To examine the sensitivity of the GEM simulations to the assumed properties of detrained ice from the deep convection scheme, three 5-day integrations were run with P3_SCPF, similar to the simulations shown above, but with different values of the ice volume-mean radius $r_{m, i}$ used to prescribe $N_{i \text { detrain }}$ of the portion of ice detrained from the deep convection scheme to the grid scale.

The following observations of observed cirrus ice crystals were used to guide the sensitivity tests. The total ice number concentration in cirrus clouds is generally between 5 and $500 \mathrm{~L}^{-1}$, with the exceptions noted in convective regions and cirrus anvils in which much higher ice number concentrations were observed (Heymsfield et al. 2017; Garrett et al. 2005).
Garrett et al. (2005), Jensen et al. (2009), and Frey et al. (2011), examined the evolution of tropical cirrus anvils using in situ measurements. Garrett et al. (2005) showed that ice crystals smaller than $50 \mu \mathrm{m}$ dominated the size distributions in cirrus anvils. Frey et al. (2011) distinguished the properties of clouds within young outflow events in contrast to aged outflow events. For clouds within young outflow events, they observed ice crystal number concentrations of up to $8300 \mathrm{~L}^{-1}$ with $r_{e, i}$ of about $90 \mu \mathrm{m}$. In contrast, clouds within aged outflow events have reduced IWC and $r_{e, i}$ due to sedimentation over the anvil lifetime. Jensen et al. (2009) also showed the ability of the strong updrafts in fresh outflow to loft large ice crystals into the upper troposphere. In their sampled anvil cirrus, they derived $r_{e, i}$ ranging from 30 to $60 \mu \mathrm{m}$. Schumann et al. (2011) discussed the ratio between $r_{m, i}$ (used in modelization) and $r_{e, i}$ (derived from in situ measurements) of ice crystals in cirrus. This ratio ranges from 0.4 to 1.1 with a mean value of 0.7 for a $r_{m, i}$ less than $55 \mu \mathrm{m}$. According to the results of these studies, $r_{m, i}$ of 20,40 , and $60 \mu \mathrm{m}$ have been chosen to prescribe $N_{i \text { detrain }}$ from the deep convection scheme in P3 in the three sensitivity tests using P3_SCPF but with a modified coupling to the convection; these runs are referred to as P3_SCPF_Rmi20, P3_SCPF_Rmi40, and P3_SCPF_Rmi60, respectively.

Figure 14 shows vertical profiles of the CWC and IWC and the $\mathrm{CF}$, averaged in time and in space, as seen by the radiation scheme. The tendencies for $T$ and $Q$ are shown in Figs. 15 and 16 , respectively. In the mid and upper troposphere, an increase in the prescribed volume-mean radius of ice particles detrained from the deep convection scheme into P3 results in less IWC with maximum values between $14 \times 10^{-3}$ and $11 \times 10^{-3} \mathrm{~g} \mathrm{~kg}^{-1}$ 
(a) Short-Wave Radiation

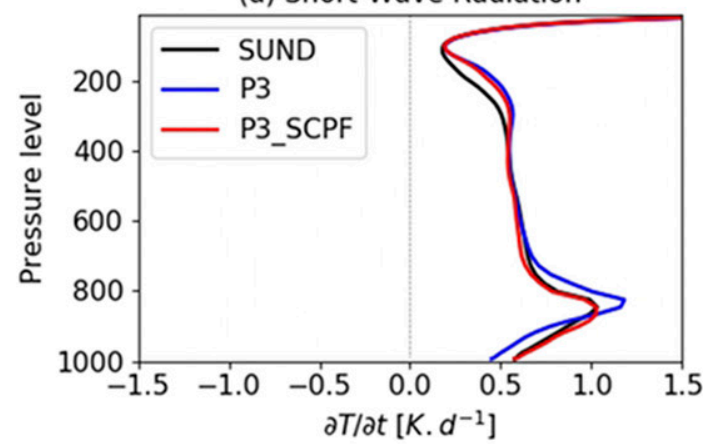

(c) Deep convection

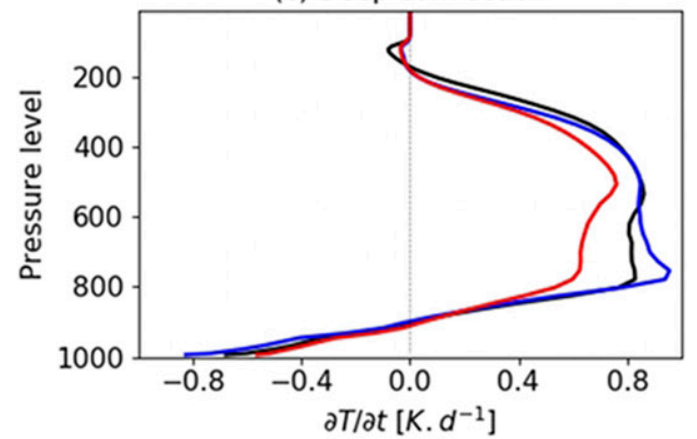

(e) Shallow convection

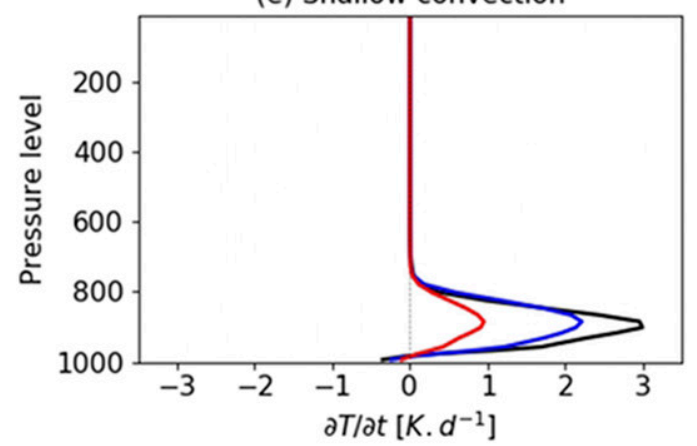

(g) Physics (solid) and dynamics (dashed)

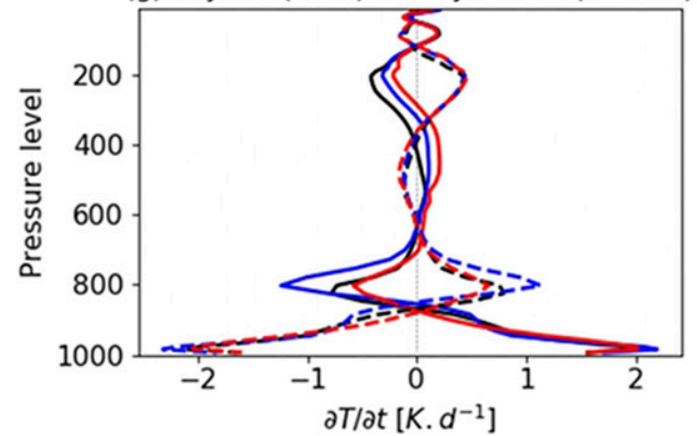

(b) Longwave-Wave Radiation

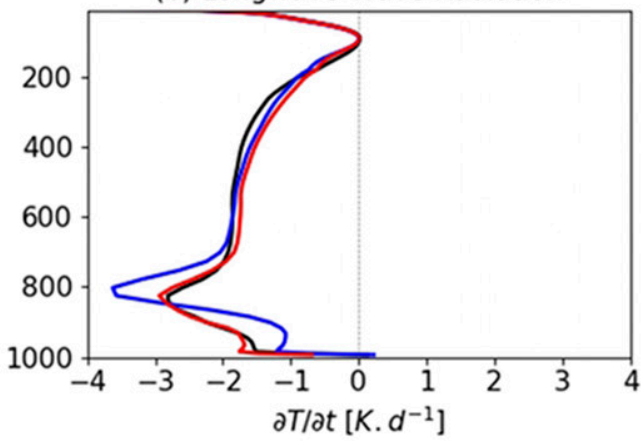

(d) Explicit condensation

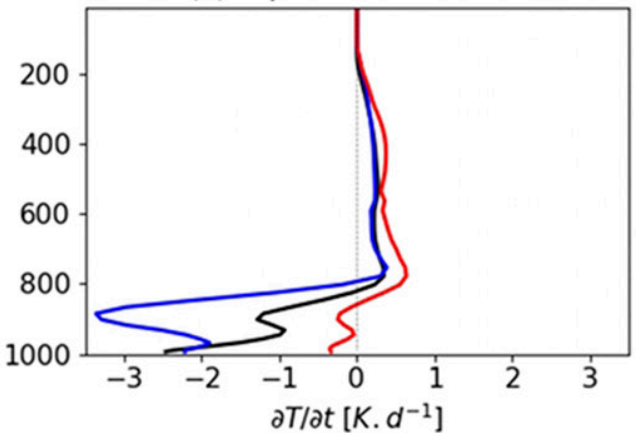

(f) Boundary layer

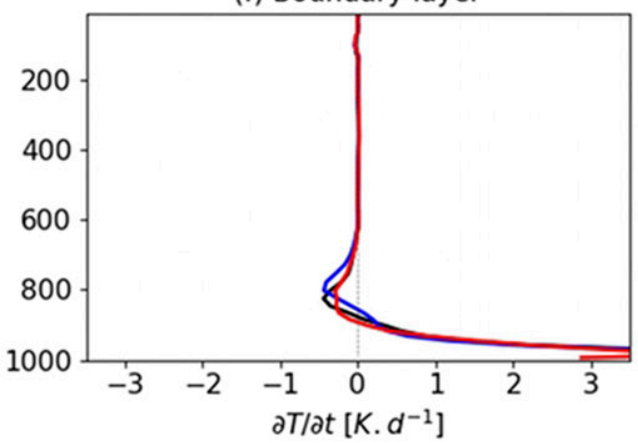

(h) Sum of tendencies

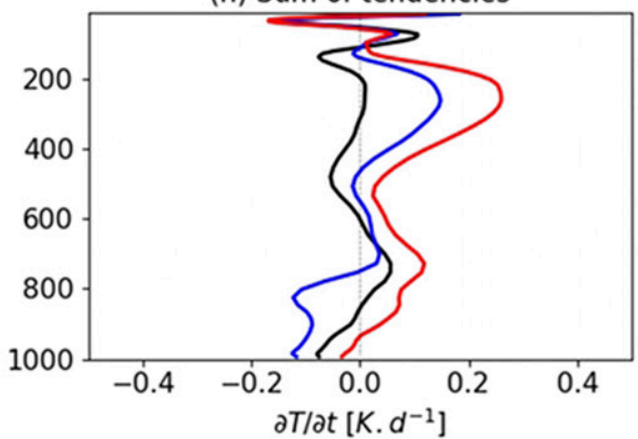

FIG. 12. Profiles of temperature tendencies averaged in time (a 5-day forecast) and space (global), using the SUND, P3, and P3_SCPF configurations of the forecast model: (a) shortwave radiation, (b) longwave radiation, (c) deep convection, (d) explicit condensation, (e) shallow convection, (f) boundary layer, (g) dynamics and combined-physics tendencies, and (h) the sum of all tendencies. Pressure levels are shown in hPa. 
(a) Deep convection

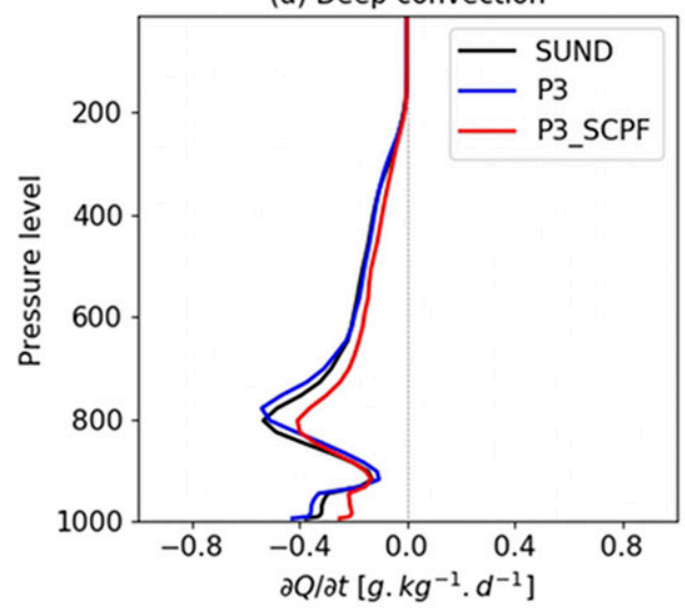

(c) Shallow convection

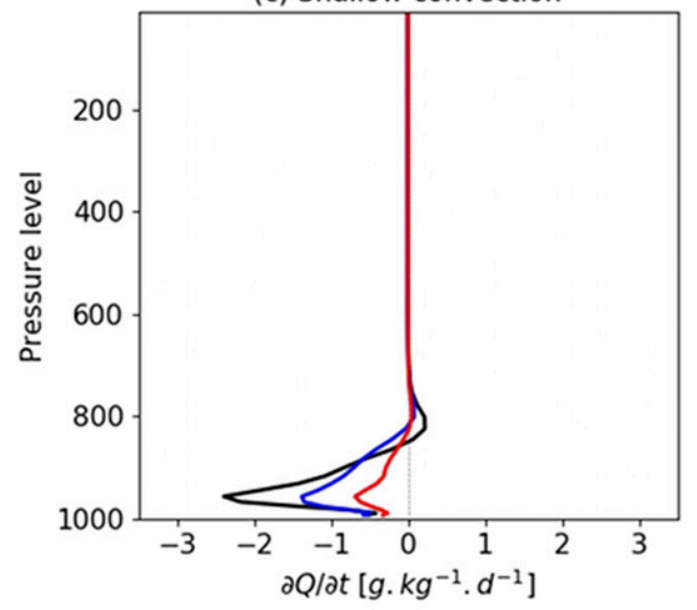

(e) Physics (solid) and dynamics (dashed)

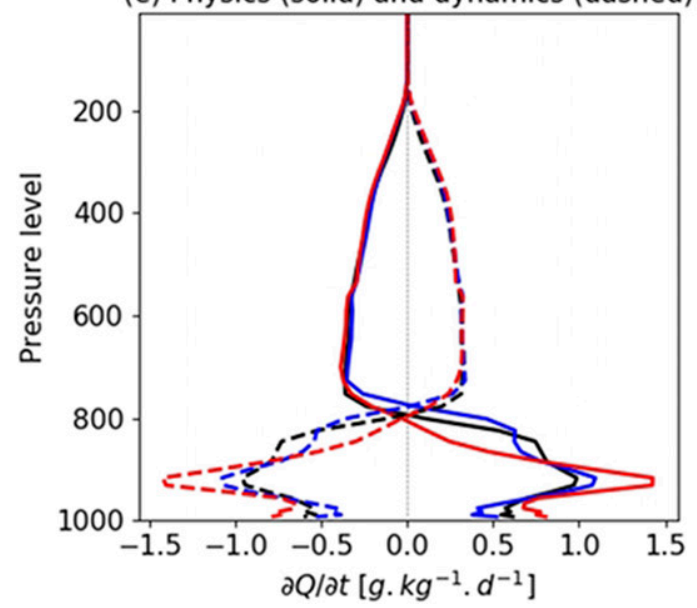

(b) Explicit condensation

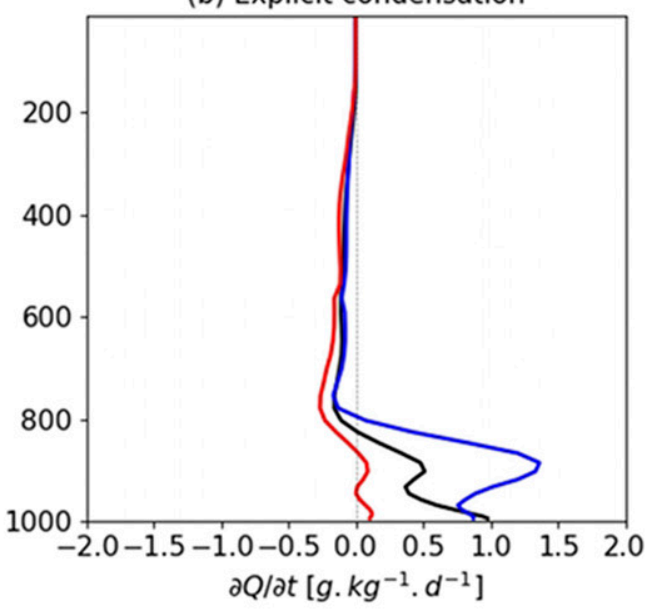

(d) Boundary layer

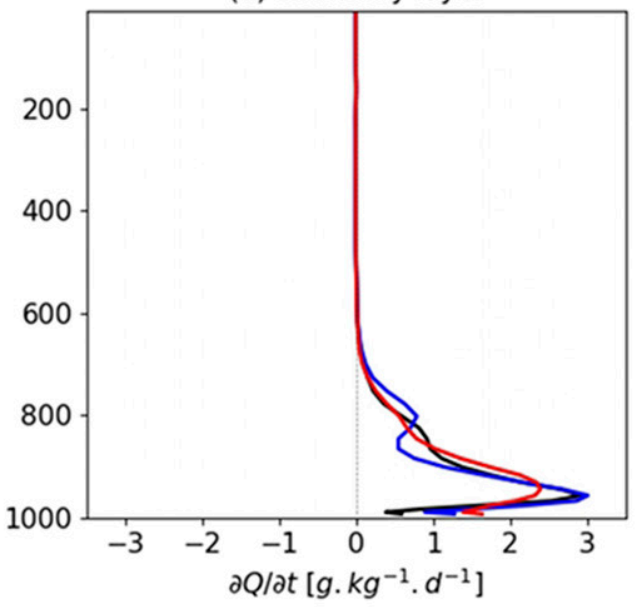

(f) Sum of tendencies

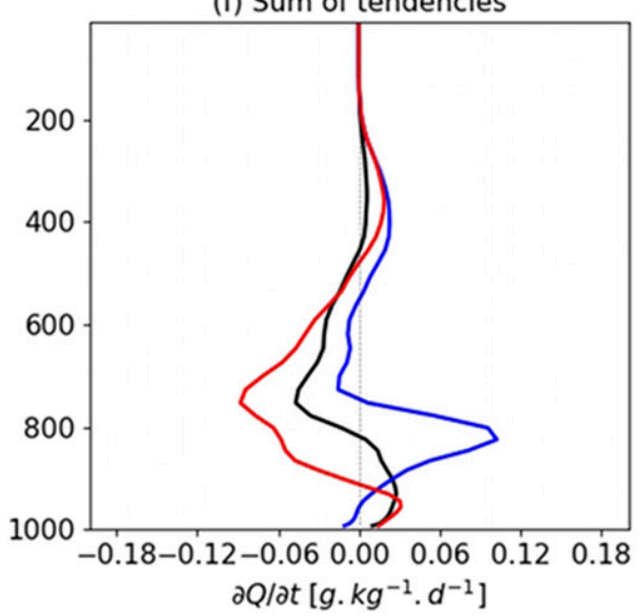

FIG. 13. Profiles of moisture tendencies averaged in time (a 5-day forecast) and space (global), using the SUND, P3, and P3_SCPF configurations of the forecast model: (a) deep convection, (b) explicit condensation, (c) shallow convection, (d) boundary layer, (e) dynamics and combined-physics tendencies, and (f) the sum of all tendencies. Pressure levels are shown in $\mathrm{hPa}$. 

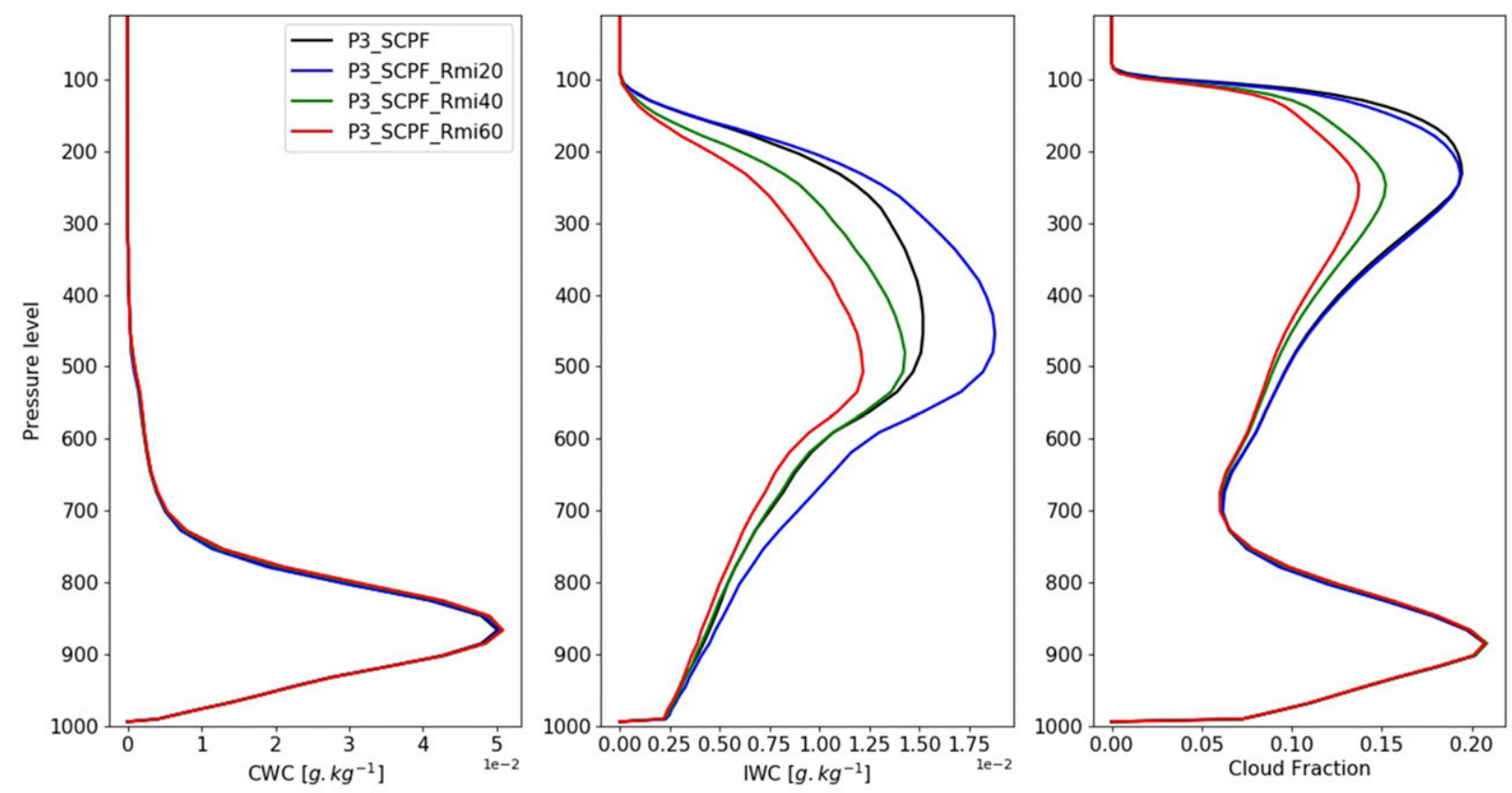

FIG. 14. As in Fig. 11, but for the experiment P3_SCPF (black) with an volume mean radius prescribed at $20 \mu \mathrm{m}$ (P3_SCPF_Rmi20; blue), $40 \mu \mathrm{m}$ (P3_SCPF_Rmi40; green), and $60 \mu \mathrm{m}$ (P3_SCPF_Rmi60; red) to derive $N_{i \_ \text {detrain }}$ from the deep convection scheme into the explicit P3 scheme.

for detrained $r_{m, i}$ of 60 and $40 \mu \mathrm{m}$. The $\mathrm{CF}$ is also lower (Figs. 14b,c). The CF from P3_SCPF is similar to that of P3_SCPF_Rmi20, suggesting that our default configuration of P3_SCPF leads to a higher number mixing ratio of small ice crystals for detrained condensate.

Changes in the CF and IWC mostly affect the $T$ tendency from both shortwave and the longwave radiation (Figs. 15a,b). Table 4 gives the average TOA radiative fluxes for the three simulations. As the detrained ice particle volume-mean radius increases, the IWC in mid and upper levels decreases and the effects of high cloud trapping longwave radiation and reflecting shortwave radiation decrease leading to a smaller temperature tendency from the radiation scheme (Figs. 15a,b). This leads to a profile of total temperature tendency, which is the sum of tendencies from all of the physics schemes, close to zero for P3_SCPF_Rmi60 (Fig. 15h). Impacts on the tendency for moisture from all of the physics schemes are weak (Fig. 16).

The impact on the overall model results are examined by running the 2016-17 summer series using the P3_SCPF_ Rmi60 configuration. Comparisons were made to skill scores from the P3_SCPF configuration (with the original coupling to convection) and to those from SUND, which is the reference configuration for these global GEM runs. As seen in Figs. 17 and 18, P3_SCPF_Rmi60 shows a clear improvement in biases and standard deviation of $T$ errors against radiosonde compared to P3_SCPF over almost the entire column for the entire integration period, and over all regions examined. This has a substantial impact on radiative effects in the middle and upper troposphere associated with anvil cirrus. The all sky OLR at the TOA in Fig. 4d shows that the cirrus anvil cover that was overestimated in the convective areas of the tropics in P3 (Fig. 4c) get closers to observations in P3_ SCPF_Rmi60. This sensitivity to the characteristics of detrained hydrometeors is consistent with the study of Grell et al. (2018), who showed that detrained hydrometeor characteristics have a significant impact on cloud properties as well as precipitation.

The modification to detrainment assumptions in P3_SCPF_ Rmi60 shows clear improvements in the upper-air scores compared to P3_SCPF (Figs. 17 and 18) and to the original P3 (not shown). When compared to SUND, our global GEM reference model configuration, P3_SCPF_Rmi60 has some dramatic improvement on the bias of $T$ and $Z_{g}$ at $24 \mathrm{~h}$ (Fig. 19), though with some degradation of the standard deviation of $Z_{g}$ errors at upper levels (Fig. 19a). By day 5, there is a mix of improvements and degradations (Fig. 20). Precipitation (not shown) continues to be much higher with P3_SCPF_Rmi60 and is likely excessive. We remark that unlike with P3, the moist physics and radiation schemes have been tuned and calibrated for optimal balance over the years for use with the Sundqvist scheme. Overall, therefore, this is an encouraging result for the prospect of eventually using the modified P3 scheme in a large-scale operational NWP system.

\section{Summary and discussion}

The P3 microphysics scheme has been modified to include a parameterization for the subgrid-scale clouds and precipitation fractions (SCPF) for use in atmospheric models with horizontal grid spacings large enough that unresolved clouds 
(a) Short-Wave Radiation

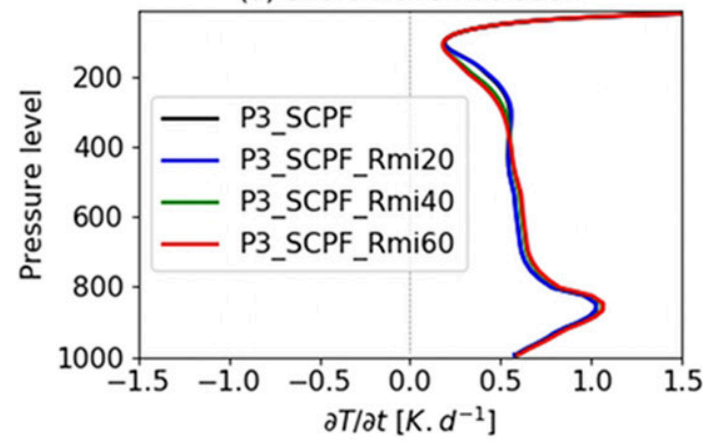

(c) Deep convection

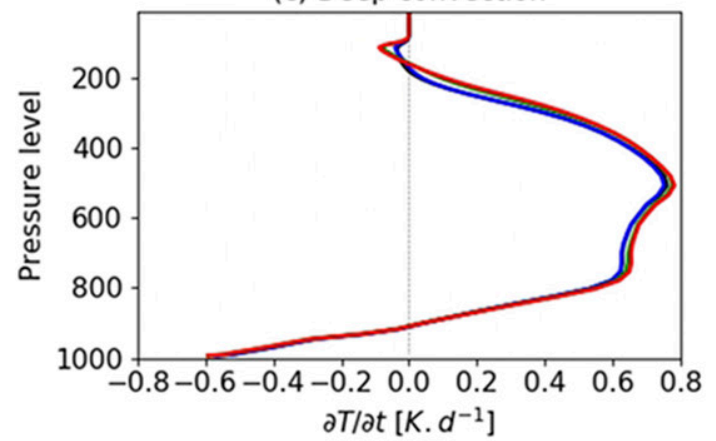

(e) Shallow convection

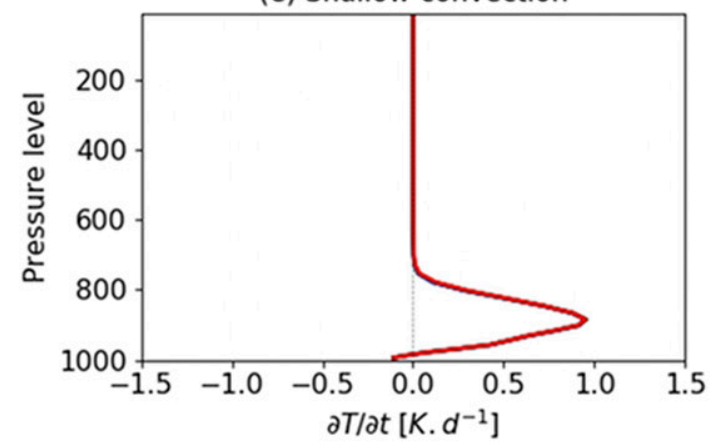

(g) Physics (solid) and dynamics (dashed)

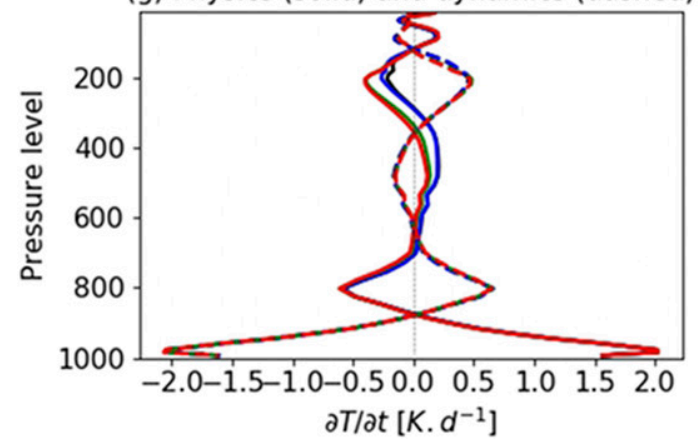

(b) Longwave-Wave Radiation

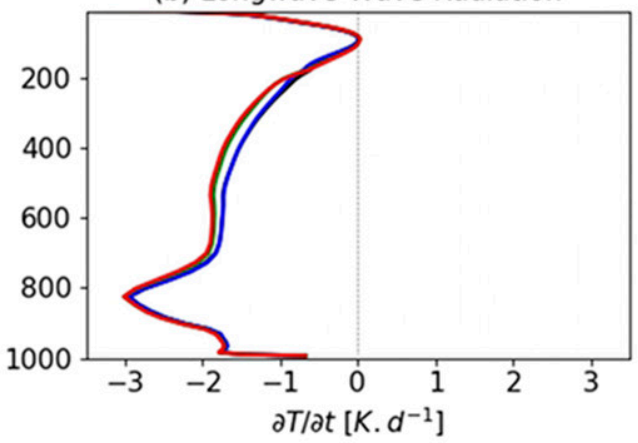

(d) Explicit condensation

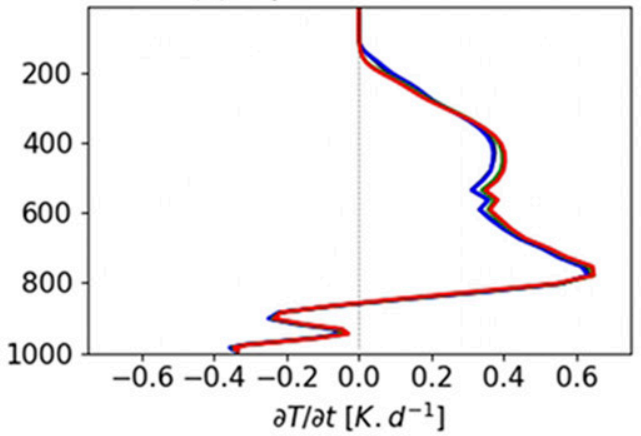

(f) Boundary layer

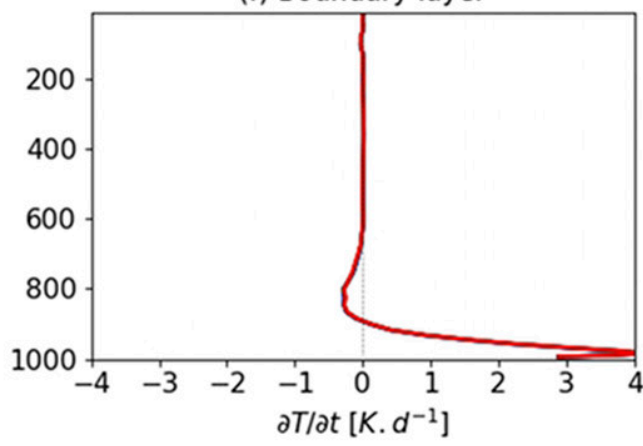

(h) Sum of tendencies

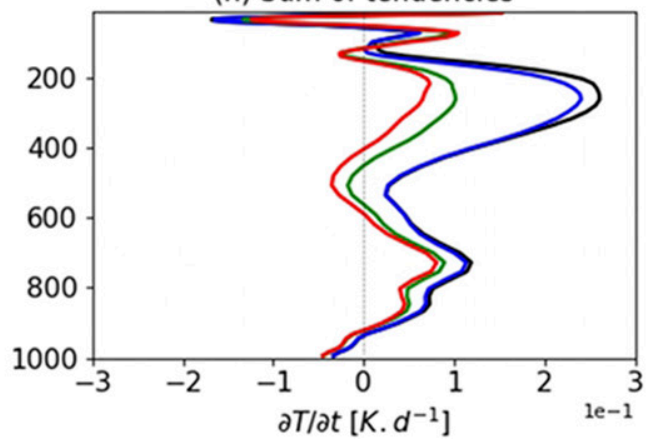

FIG. 15. As in Fig. 12, but for the experiment P3_SCPF (black) and with an volume mean radius prescribed at $20 \mu \mathrm{m}$ (P3_SCPF_Rmi20; blue), $40 \mu \mathrm{m}$ (P3_SCPF_Rmi40; green), and $60 \mu \mathrm{m}$ (P3_SCPF_Rmi60; red) to derive $N_{i}$ detrain from the deep convection scheme into the explicit P3 scheme. 
(a) Deep convection

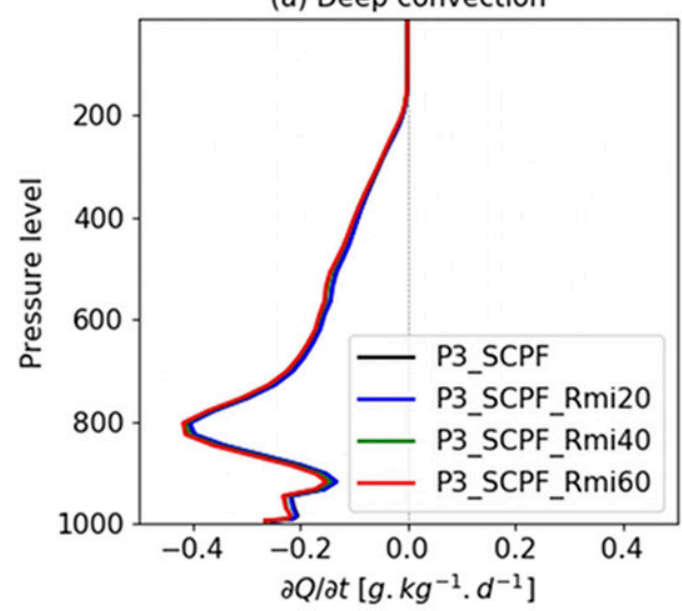

(c) Shallow convection

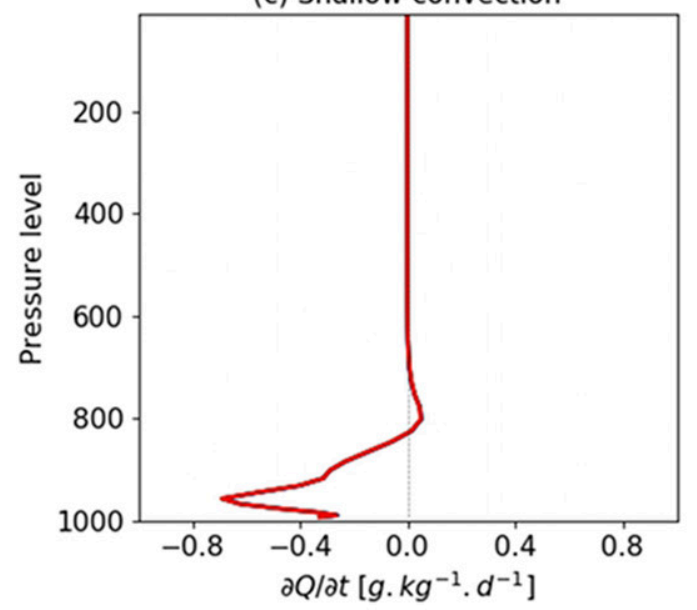

(e) Physics (solid) and dynamics (dashed)

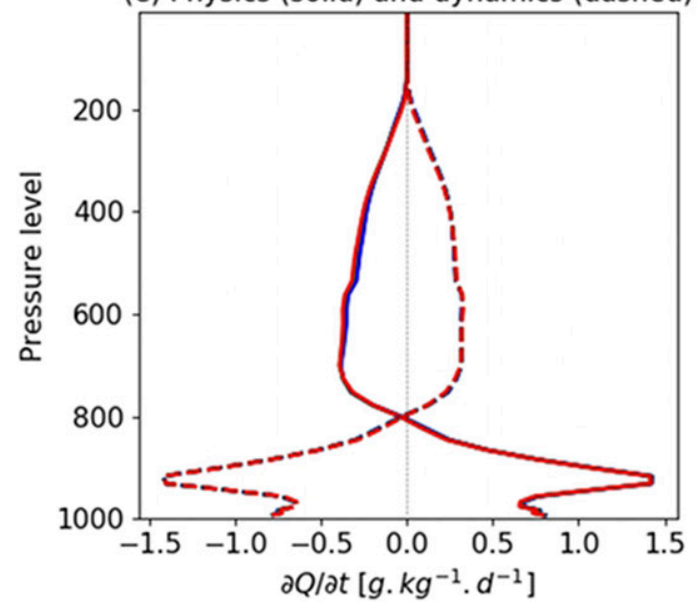

(b) Explicit condensation

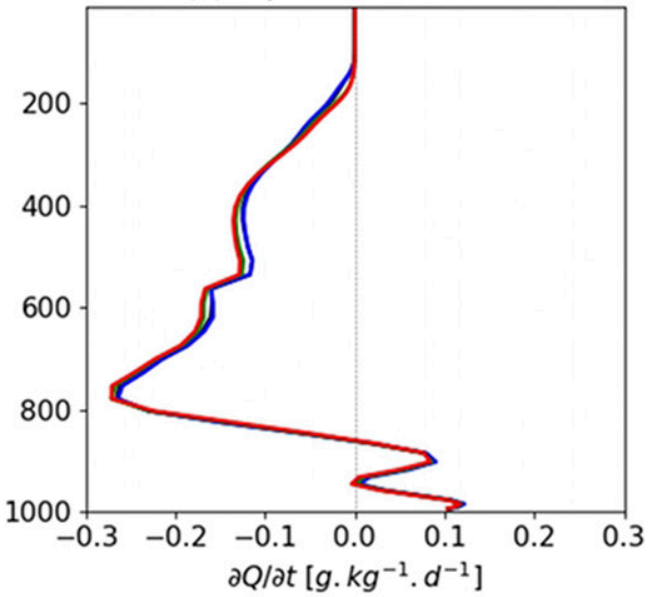

(d) Boundary layer

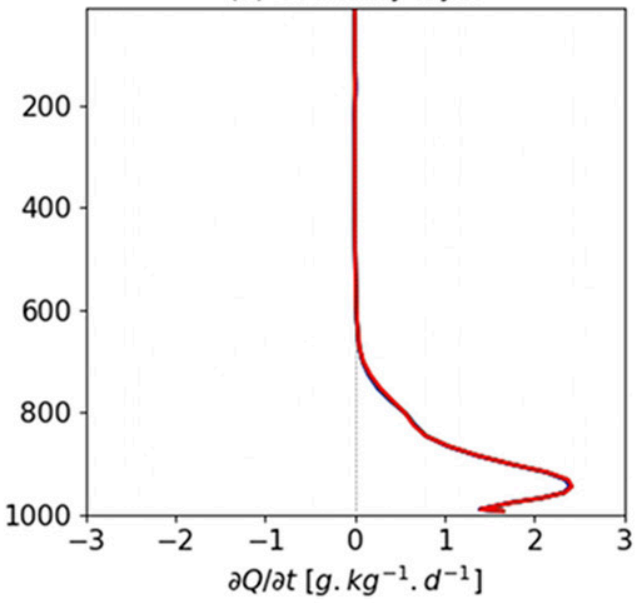

(f) Sum of tendencies

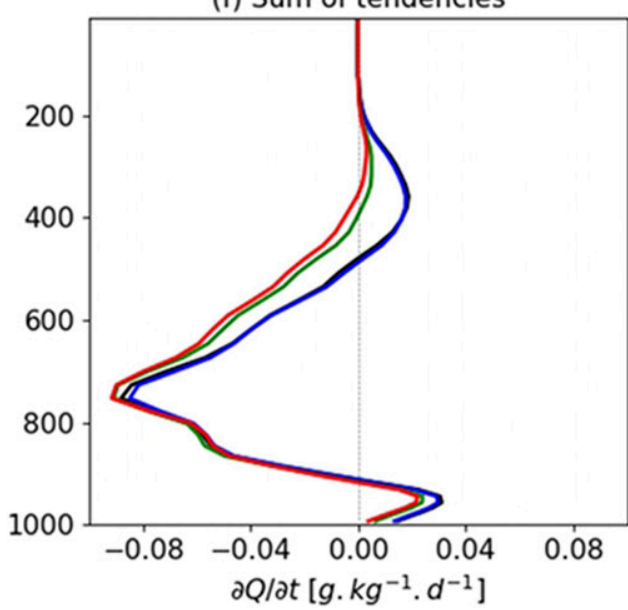

FIG. 16. As in Fig. 13, but for the experiment P3_SCPF (black) with an volume mean radius prescribed at $20 \mu \mathrm{m}$ (P3_SCPF_Rmi20; blue), $40 \mu \mathrm{m}$ (P3_SCPF_Rmi40; green), and $60 \mu \mathrm{m}$ (P3_SCPF_Rmi60; red) to derive $N_{i \_ \text {detrain }}$ from the deep convection scheme into the explicit $\mathrm{P} 3$ scheme. 


\section{Lead Time: $24 \mathrm{~h}$ (day 1 ) \\ GLOBAL}
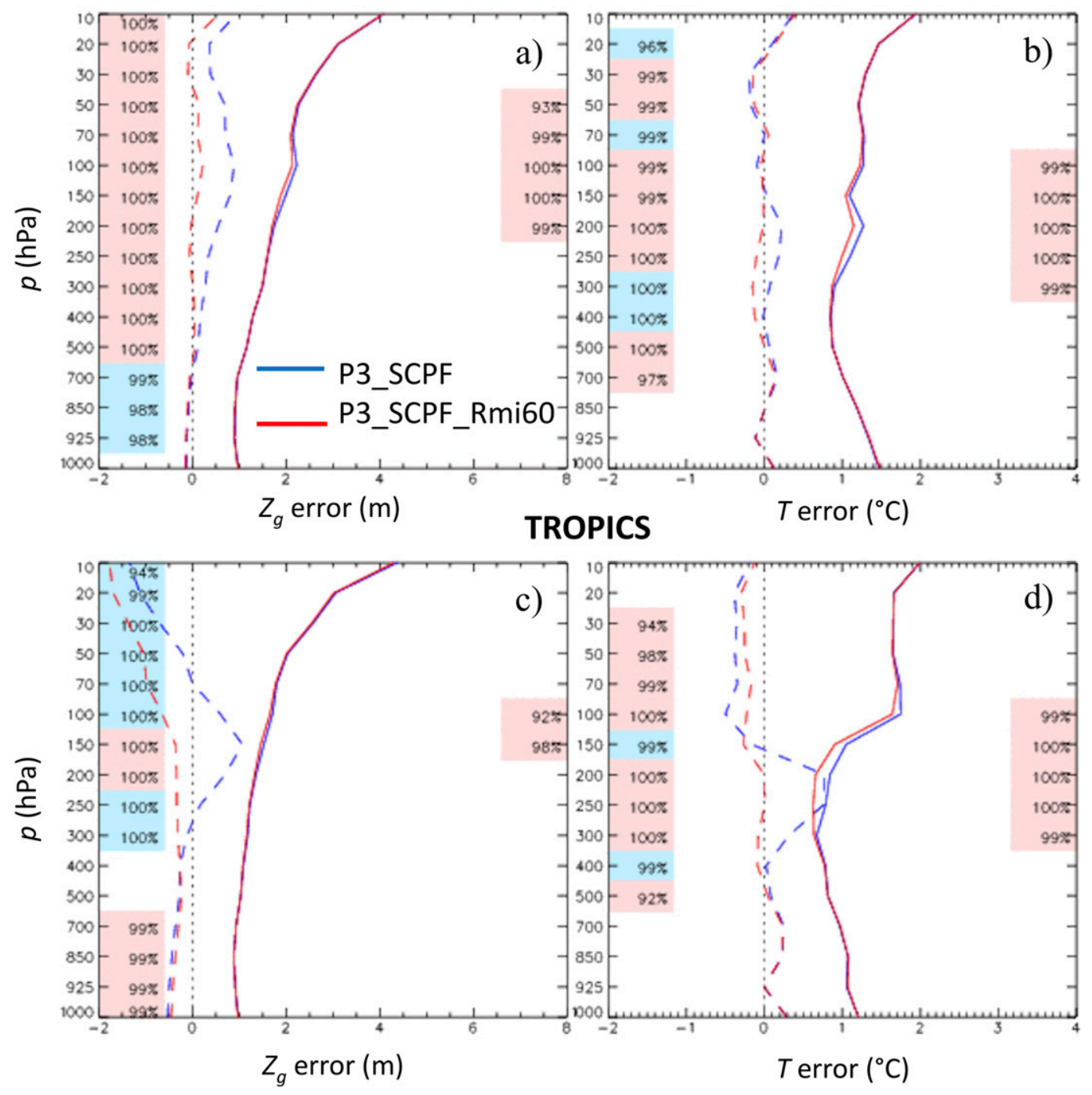

FIG. 17. As in Fig. 5, but for experiment P3_SCPF_Rmi60 (in red) compared to P3_SCPF (in blue) on day 1.

contribute significantly to the overall simulation or numerical forecast. After testing in a simple 1D kinematic model, the modified scheme was tested in the GEM model using an operational global NWP configuration with $25-\mathrm{km}$ horizontal grid spacing. Various series of 5-day forecasts were run and compared using standard forecast skill metrics of common meteorological fields computed against radiosonde and surface observations. Different gridscale condensation schemes were used, including Sundqvist and P3, the latter with and without the new SCPF component activated. The tendencies for various state variables from different physical parameterization schemes were examined using a model tendency diagnostic package. This helped to identify the need to modify the coupling between the deep convection scheme and the microphysics. Sensitivity tests were then performed with modifications to the assumed physical properties of hydrometeors detrained from the convective scheme to the gridscale microphysics.

Since the Sundqvist scheme is used in most operational NWP systems in Canada, the series of global GEM runs using Sundqvist was treated as a control against which results with the modified P3 scheme were compared. As with most experiments in which a major component is replaced with another, the results in terms of scores were a mix of improvements and deteriorations. After $24 \mathrm{~h}$, the modified P3_SCPF with a detrained ice size of $60 \mu \mathrm{m}$ (P3_SCPF_Rmi60) resulted in some significant improvements, in terms of both magnitude and statistical significance, to the bias in temperature and geopotential heights throughout the troposphere and stratosphere compared to 


\section{Lead Time: $120 \mathrm{~h}$ (day 5) \\ GLOBAL}
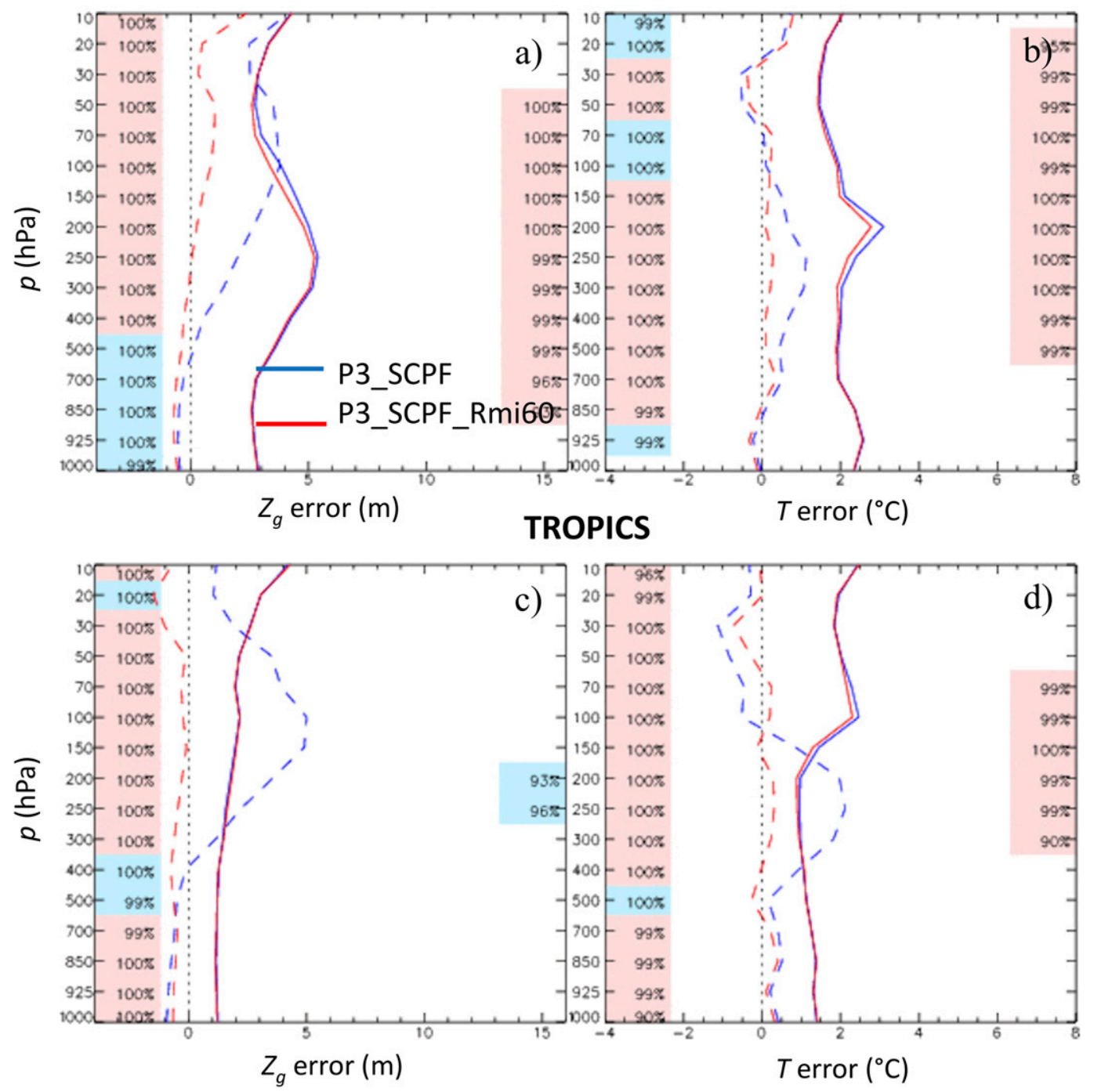

FIG. 18. As in Fig. 17, but for experiment P3_SCPF_Rmi60 (in red) compared to P3_SCPF (in blue) on day 5.

Sundqvist. By day 5, the upper-air temperature biases were net neutral while the biases in geopotential height continued to be improved compared to the runs with Sundqvist. On the other hand, by day 5 the error standard deviation of these fields was degraded, particularly in the boundary layer and at the jet level. Further, an already excessively moist precipitation bias was exacerbated with the switch to the modified P3. The strong sensitivity of the short- and medium-range meteorological guidance quality to the cirrus anvil clouds and their optical properties, seen in these results, highlight the necessity to carefully study and evaluate the quality of the forecast cirrus coverage, microphysical and optical properties.

Nevertheless, the results are very promising overall considering that the GEM model with Sundqvist has been well calibrated and balanced with other physical parameterization schemes over many years to produce optimal results. In contrast, no tuning was done with the use of P3 in this study other than the implementation of the SCPF and the adjustment to the assumed size of ice detrained from the deep convection scheme. To replace Sundqvist with P3 in MSC's global deterministic system or other NWP systems for use operationally will require a recalibration and rebalancing of the package of moist physics schemes in GEM. Other changes to P3 specifically may also be required, such as the specification of the critical relative humidity threshold $\left(\mathrm{RH}_{\mathrm{cr}}\right)$ for the diagnostic cloud fraction that could, for example, be modified based on observational data or even to vary in time (Quaas 2012). Microphysical process rates may also need to be modified further based on the cloud fraction in order to address 


\section{Lead Time: $24 \mathrm{~h}$ (day 1$)$ \\ GLOBAL}
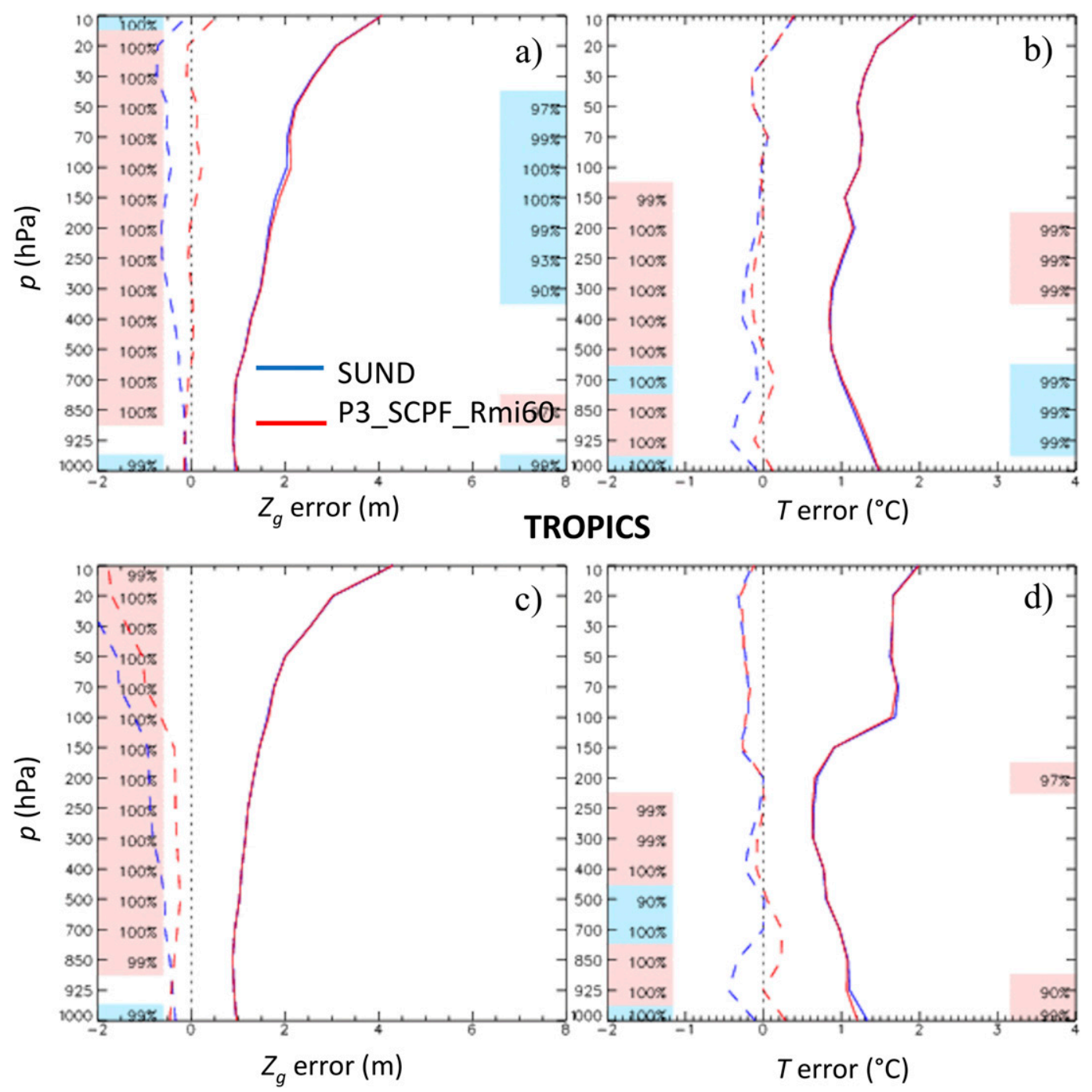

FIG. 19. As in Fig. 18, but for experiment P3_SCPF_Rmi60 (in red) compared to SUND (in blue) on day 1.

the problem of excess precipitation. The replacement of Sundqvist with $\mathrm{P} 3$ resulted in an average doubling of the total integration time in the $25-\mathrm{km}$ runs, mainly due to a combination of a more complex scheme (and with substepping), and more prognostic variables to advect in dynamics. One possible optimization would be to simplify $\mathrm{P} 3$ and reduce the number of prognostic fields for large-scale (e.g., get rid of the two variables for rimed ice). Note also, by going from 25 to $15 \mathrm{~km}$ (e.g., McTaggart-Cowan et al. 2019), the model time step drops by $40 \%$, thus so should the amount of substepping for P3.

This current study is the latest in the series of advances in the P3 microphysics scheme toward developing it into a versatile gridscale condensation scheme, usable for a variety of weather conditions and over a wide range of spatial scales in atmospheric models. The original P3 scheme proposed in MM15a represented a unique way to represent ice-phase hydrometeors in bulk microphysics schemes. In Milbrandt and Morrison (2016), P3 was expanded to allow for multiple free ice-phase categories. Cholette et al. (2019) added the capability to simulated mixed-phase particles through the addition of a predicted liquid fraction. Paukert et al. (2019) implemented a three-moment rain parameterization, improving the process rates related to rain. Milbrandt et al. (2020) developed a three-moment representation of ice in P3, significantly improving its ability to represent hail. With the implementation of the SCPF in this study, P3 can now be used in model configurations coarser than cloud-resolving and holds promise for eventual use in large-scale NWP systems. 


\section{Lead Time: $120 \mathrm{~h}$ (day 5)}

\section{GLOBAL}
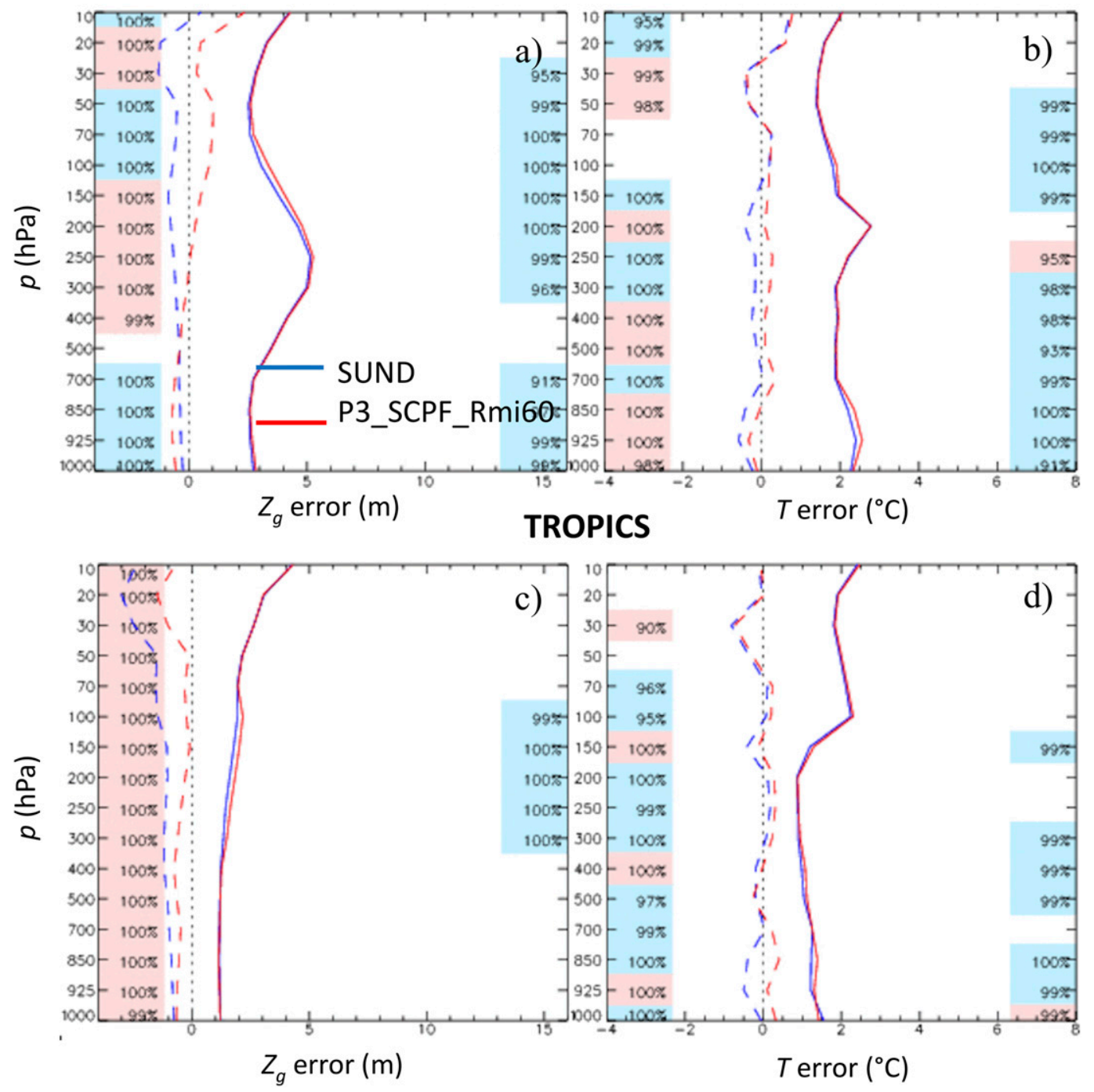

FIG. 20. As in Fig. 20, but for experiment P3_SCPF_Rmi60 (in red) compared to SUND (in blue) on day 5.

Acknowledgments. The authors thank Michel Roch and Jing Yang for developments to the diagnostic tools throughout this work.

\section{REFERENCES}

Bechtold, P., E. Bazile, F. Guichard, P. Mascart, and E. Richard, 2001: A mass-flux convection scheme for regional and global models. Quart. J. Roy. Meteor. Soc., 127, 869-886, https:// doi.org/10.1002/qj.49712757309.

Bélair, S., L.-P. Crevier, J. Mailhot, B. Bilodeau, and Y. Delage, 2003: Operational implementation of the ISBA land surface scheme in the Canadian regional weather forecast model. Part I: Warm season results. J. Hydrometeor., 4, 352-370, https:// doi.org/10.1175/1525-7541(2003)4<352:OIOTIL>2.0.CO;2.

_ J J. Mailhot, C. Girard, and P. Vaillancourt, 2005: Boundary layer and shallow cumulus clouds in a medium-range forecast of a large-scale weather system. Mon. Wea. Rev., 133, 19381960, https://doi.org/10.1175/MWR2958.1.

Boudala, F. S., G. A. Isaac, S. G. Cober, and Q. Fu, 2004: Liquid fraction in stratiform mixed-phase clouds from in situ observations. Quart. J. Roy. Meteor. Soc., 130, 2919-2931, https:// doi.org/10.1256/qj.03.153.

Bryan, G. H., J. C. Wyngaard, and J. M. Fritsch, 2003: Resolution requirements for the simulation of deep moist convection. Mon. Wea. Rev., 131, 2394-2416, https://doi.org/10.1175/15200493(2003)131<2394:RRFTSO>2.0.CO;2.

Buehner, M., and Coauthors, 2015: Implementation of deterministic weather forecast systems based on ensemble-variational data assimilation at Environment Canada. Part I: The global system. Mon. Wea. Rev., 143, 2532-2559, https://doi.org/ 10.1175/MWR-D-14-00354.1.

Charney, J. G., and N. A. Phillips, 1953: Numerical integration of the quasi geostrophic equations for barotropic and simple 
baroclinic flows. J. Meteor., 10, 71-99, https://doi.org/10.1175/ 1520-0469(1953)010<0071:NIOTQG > 2.0.CO;2.

Cholette, M., H. Morrison, J. A. Milbrandt, and J. M. Thériault, 2019: Parameterization of the bulk liquid fraction on mixedphase particles in the Predicted Particle Properties (P3) scheme: Description and idealized simulations. J. Atmos. Sci., 76, 561-582, https://doi.org/10.1175/JAS-D-18-0278.1.

Chosson, F., P. A. Vaillancourt, J. A. Milbrandt, M. K. Yau, and A. Zadra, 2014: Adapting two-moment microphysics schemes across model resolutions: Subgrid cloud and precipitation fraction and microphysical sub-time step. J. Atmos. Sci., 71, 2635-2653, https://doi.org/10.1175/JAS-D-13-0367.1.

Cooper, W. A., 1986: Ice initiation in natural clouds. Precipitation Enhancement: A Scientific Challenge, Meteor. Monogr., No. 43, Amer. Meteor. Soc., 29-32.

Côté, J., S. Gravel, A. Méthot, A. Patoine, M. Roch, and A. Staniforth, 1998: The operational CMC-MRD Global Environmental Multiscale (GEM) model. Part I: Design considerations and formulation. Mon. Wea. Rev., 126, 1373-1395, https://doi.org/10.1175/1520-0493(1998)126<1373: TOCMGE $>2.0 . \mathrm{CO} ; 2$.

Dietlicher, R., D. Neubauer, and U. Lohmann, 2018: Prognostic parameterization of cloud ice with a single category in the aerosol-climate model ECHAM(v6.3.0)-HAM(v2.3). Geosci. Model Dev., 11, 1557-1576, https://doi.org/10.5194/gmd-111557-2018.

Doelling, D. R., and Coauthors, 2013: Geostationary enhanced temporal interpolation for CERES flux products. J. Atmos. Oceanic Technol., 30, 1072-1090, https://doi.org/10.1175/ JTECH-D-12-00136.1.

—, M. Sun, L. T. Nguyen, M. L. Nordeen, C. O. Haney, D. F. Keyes, and P. E. Mlynczak, 2016: Advances in geostationaryderived longwave fluxes for the CERES synoptic (SYN1deg) product. J. Atmos. Oceanic Technol., 33, 503-521, https:// doi.org/10.1175/JTECH-D-15-0147.1.

Forbes, R., A. Tompkins, and A. Untch, 2012: A new prognostic bulk microphysics scheme for the IFS. ECMWF Tech. Memo. 649, 30 pp., https://www.ecmwf.int/sites/default/files/elibrary/ 2011/9441-new-prognostic-bulk-microphysics-scheme-ifs.pdf.

Frey, W., and Coauthors, 2011: In situ measurements of tropical cloud properties in the West African Monsoon: Upper tropospheric ice clouds, mesoscale convective system outflow, and subvisual cirrus. Atmos. Chem. Phys., 11, 5569-5590, https://doi.org/10.5194/acp-11-5569-2011.

Garrett, T. J., and Coauthors, 2005: Evolution of a Florida cirrus anvil. J. Atmos. Sci., 62, 2352-2372, https://doi.org/10.1175/ JAS3495.1.

Geleyn, J. F., and A. Hollingsworth, 1979: An economical analytical method for the computation of the interaction between scattering and line absorption of radiation. Beitr. Phys. Atmos., 52, 1-16.

Girard, C., and Coauthors, 2014: Staggered vertical discretization of the Canadian Environmental Multiscale (GEM) model using a coordinate of the log-hydrostatic-pressure type. Mon. Wea. Rev., 142, 1183-1196, https://doi.org/10.1175/MWR-D13-00255.1.

Grell, E. D., J. Bao, D. E. Kingsmill, and S. A. Michelson, 2018: On the importance of a consistent treatment of prognostic moisture variables between convective and microphysical parameterizations. Mon. Wea. Rev., 146, 1527-1548, https://doi.org/ 10.1175/MWR-D-17-0305.1.

Grell, G. A., and S. R. Freitas, 2014: A scale and aerosol aware stochastic convective parameterization for weather and air quality modeling. Atmos. Chem. Phys., 14, 5233-5250, https:// doi.org/10.5194/acp-14-5233-2014.

Heymsfield, A. J., and Coauthors, 2017: Cirrus clouds. Ice Formation and Evolution in Clouds and Precipitation, Meteor. Monogr., No. 58, 2.1-2.26, https://doi.org/10.1175/AMSMONOGRAPHS-D16-0010.1.

IPCC, 2013: Climate Change 2013: The Physical Science Basis. Cambridge University Press, 1535 pp., https://doi.org/10.1017/ CBO9781107415324.

Jensen, E. J., and Coauthors, 2009: On the importance of small ice crystals in tropical anvil cirrus. Atmos. Chem. Phys., 9, 55195537, https://doi.org/10.5194/acp-9-5519-2009.

Jiang, J. H., and Coauthors, 2012: Evaluation of cloud and water vapor simulations in CMIP5 climate models using NASA "ATrain” satellite observations. J. Geophys. Res., 117, D14105, https://doi.org/10.1029/2011JD017237.

Kain, J. S., and J. M. Fritsch, 1990: A one-dimensional entraining/ detraining plume model and its application in convective parameterization. J. Atmos. Sci., 47, 2784-2802, https://doi.org/ 10.1175/1520-0469(1990)047<2784:AODEPM>2.0.CO;2.

— , and - 1993: Convective parameterization for mesoscale models: The Kain-Fritsch scheme.The Representation of Cumulus Convection in Numerical Models, Meteor. Monogr., No. 24, Amer. Meteor. Soc., 165-170.

Klein, S., and C. Jakob, 1999: Validation and sensitivities of frontal clouds simulated by the ECMWF model. Mon. Wea. Rev., 127, 2514-2531, https://doi.org/10.1175/1520-0493(1999)127<2514: VASOFC $>2.0 . \mathrm{CO} ; 2$.

Laroche, S., and R. Sarrazin, 2013: Impact of radiosonde balloon drift on numerical weather prediction and verification. Wea. Forecasting, 28, 772-782, https://doi.org/10.1175/WAF-D-1200114.1.

Lebo, Z. J., and H. Morrison, 2015: Effects of horizontal and vertical grid spacing on mixing in simulated squall lines and implications for convective strength and structure. Mon. Wea. Rev., 143, 4355-4375, https://doi.org/10.1175/MWR-D15-0154.1.

Lemay, F., and T. Husson, 2017: Emet or forecast verification using the power of a relational database. Seventh Int. Verification Methods Workshop, Berlin, Germany, Deutscher Wetterdienst, P OPS SOFT-7, https://www.7thverificationworkshop.de/ Ressourcen/Annalen_51_komplett.pdf.

Lespinas, F., V. Fortin, G. Roy, P. Rasmussen, and T. Stadnyk, 2015: Performance evaluation of the Canadian Precipitation Analysis (CaPA). J. Hydrometeor., 16, 2045-2064, https:// doi.org/10.1175/JHM-D-14-0191.1.

Li, J., and H. W. Barker, 2005: A radiation algorithm with correlated-k distribution. Part I: Local thermal equilibrium. J. Atmos. Sci., 62, 286-309, https://doi.org/10.1175/JAS-3396.1.

Lin, Y.-L., R. D. Farley, and H. D. Orville, 1983: Bulk parameterization of the snow field in a cloud model. J. Climate Appl. Meteor., 22, 1065-1092, https://doi.org/10.1175/1520-0450(1983) 022<1065:BPOTSF $>2.0 . \mathrm{CO} ; 2$.

Mahfouf, J. F., B. Brasnett, and S. Gagnon, 2007: A Canadian precipitation analysis (CaPA) project: Description and preliminary results. Atmos.-Ocean, 45, 1-17, https://doi.org/ 10.3137/ao.v450101.

McTaggart-Cowan, R., and Coauthors, 2019: Modernization of atmospheric physics parameterization in Canadian NWP. J. Adv. Model. Earth Syst., 11, 3593-3635, https://doi.org/ 10.1029/2019MS001781.

Mesinger, F., and A. Arakawa, 1976: Numerical methods used in atmospheric models. GARP Publ. 17, 64 pp. 
Milbrandt, J. A., and H. Morrison, 2016: Parameterization of cloud microphysics based on the prediction of bulk ice particle properties. Part III: Introduction of multiple free categories. J. Atmos. Sci., 73, 975-995, https://doi.org/10.1175/JAS-D-150204.1.

- J. Theriault, and R. Mo, 2014: Modeling the phase transition associated with melting snow in a 1D kinematic framework: Sensitivity to the microphysics. Pure Appl. Geophys., 171, 303-322, https://doi.org/10.1007/s00024-012-0552-y.

—, S. Bélair, M. Faucher, M. Vallée, M. L. Carrera, and A. Glazer, 2016: The pan-Canadian high resolution $(2.5 \mathrm{~km})$ deterministic prediction system. Wea. Forecasting, 31, 17911816, https://doi.org/10.1175/WAF-D-16-0035.1.

- S. Leroyer, D. Paquin-Ricard, M. Faucher, S. Zhang, C. Jouan, 2018: High Resolution Deterministic Prediction System (HRDPS): Update from version 4.4.0 to version 5.0.0. Description of changes and forecast performance, Canadian Meteorological Center Tech. Rep., 57 pp.

Milbrandt J. A., H. Morrison, D. T. Dawson II, and M. Paukert, 2020: A triple-moment representation of ice in the Predicted Particle Properties (P3) microphysics scheme. J. Atmos. Sci., https://doi.org/10.1175/JAS-D-20-0084.1, in press.

Mo, R., M. Brugman, J. A. Milbrandt, J. Goosen, Q. Geng, C. Emond, J. Bau, and A. Erfani, 2019: Impacts of hydrometeor drift on orographic precipitation: Two case studies of landfalling atmospheric rivers in British Columbia, Canada. Wea. Forecasting, 34, 1211-1237, https://doi.org/10.1175/WAFD-18-0176.1.

Morrison, H., and J. A. Milbrandt, 2015a: Parameterization of cloud microphysics based on the prediction of bulk ice particle properties. Part I: Scheme description and idealized tests. J. Atmos. Sci., 72, 287-311, https://doi.org/10.1175/JAS-D-140065.1.

— based on the prediction of bulk ice particle properties. Part II: Case study and comparison with observations and other schemes. J. Atmos. Sci., 72, 312-339, https://doi.org/10.1175/ JAS-D-14-0066.1.
Musil, D. J., 1970: Computer modeling of hailstone growth in feeder clouds. J. Atmos. Sci., 27, 474-482, https://doi.org/ 10.1175/1520-0469(1970)027<0474:CMOHGI>2.0.CO;2.

Noilhan, J., and S. Planton, 1989: A simple parameterization of land surface processes for meteorological models. Mon. Wea. Rev., 117, 536-549, https://doi.org/10.1175/1520-0493(1989) $117<0536$ :ASPOLS $>2.0 . \mathrm{CO} ; 2$.

Paukert, M., J. Fan, P. J. Rasch, H. Morrison, J. A. Milbrandt, J. Shpund, and A. Khain, 2019: Three-moment representation of rain in a bulk microphysics model. J. Adv. Model. Earth Syst., 11, 257-277, https://doi.org/10.1029/2018MS001512.

Qaddouri, A., and V. Lee, 2011: The Canadian Global Environmental Multiscale model on the Yin-Yang grid system. Quart. J. Roy. Meteor. Soc., 137, 1913-1926, https://doi.org/10.1002/qj.873.

Quaas, J., 2012: Evaluating the "critical relative humidity" as a measure of subgrid-scale variability of humidity in general circulation model cloud cover parameterizations using satellite data. J. Geophys. Res., 117, D09208, https://doi.org/ 10.1029/2012JD017495.

Rossow, W. B., and Y.-C. Zhang, 1995: Calculation of surface and top-of-atmosphere radiative fluxes from physical quantities based on ISCCP datasets: 2. Validation and first results. J. Geophys. Res., 100, 1167-1197, https://doi.org/10.1029/ 94JD02746.

Schumann, U., B. Mayer, K. Gierens, S. Unterstrasser, P. Jessberger, A. Petzold, C. Voigt, and J. Gayet, 2011: Effective radius of ice particles in cirrus and contrails. J. Atmos. Sci., 68, 300-321, https://doi.org/10.1175/2010JAS3562.1.

Sundqvist, H., E. Berge, and J. E. Kristjansson, 1989: Condensation and cloud parameterization studies with a mesoscale numerical weather prediction model. Mon. Wea. Rev., 117, 1641-1657, https://doi.org/10.1175/1520-0493(1989)117<1641: CACPSW $>2.0 . \mathrm{CO} ; 2$.

Zadra, A., R. McTaggart-Cowan, P. A. Vaillancourt, M. Roch, S. Bélair, and A.-M. Leduc, 2014: Evaluation of tropical cyclones in the Canadian global modeling system: Sensitivity to moist process parameterization. Mon. Wea. Rev., 142, 11971220, https://doi.org/10.1175/MWR-D-13-00124.1. 